\title{
Gut Microbiota, Probiotic Interventions, and Cognitive Function in the Elderly: A Review of Current Knowledge
}

\author{
Agata Białecka-Dębek $^{1, *(\mathbb{D})}$, Dominika Granda ${ }^{1} \mathbb{D}$, Maria Karolina Szmidt $^{1}\left(\mathbb{D}\right.$ and Dorota Zielińska ${ }^{2} \mathbb{D}$ \\ 1 Department of Human Nutrition, Institute of Human Nutrition Sciences, Warsaw University of Life \\ Sciences (SGGW), Nowoursynowska 159c, 02-776 Warsaw, Poland; dominika_granda@sggw.edu.pl (D.G.); \\ maria_szmidt@sggw.edu.pl (M.K.S.) \\ 2 Department of Food Gastronomy and Food Hygiene, Institute of Human Nutrition Sciences, Warsaw \\ University of Life Sciences (SGGW), Nowoursynowska 159c, 02-776 Warsaw, Poland; \\ dorota_zielinska@sggw.edu.pl \\ * Correspondence: agata_bialecka_debek@sggw.edu.pl
}

Citation: Białecka-Dębek, A.; Granda, D.; Szmidt, M.K.; Zielińska, D. Gut Microbiota, Probiotic Interventions, and Cognitive Function in the Elderly: A Review of Current Knowledge. Nutrients 2021, 13, 2514. https://doi.org/10.3390/ nu13082514

Academic Editor:

Sandra Martin-Pelaez

Received: 1 July 2021

Accepted: 18 July 2021

Published: 23 July 2021

Publisher's Note: MDPI stays neutral with regard to jurisdictional claims in published maps and institutional affiliations.

Copyright: (c) 2021 by the authors. Licensee MDPI, Basel, Switzerland. This article is an open access article distributed under the terms and conditions of the Creative Commons Attribution (CC BY) license (https:// creativecommons.org/licenses/by/ $4.0 /)$

\begin{abstract}
Changes in the composition and proportions of the gut microbiota may be associated with numerous diseases, including cognitive impairment. Over the recent years, the growing interest in this relation is observed, but there are still many unknowns, especially in the elderly. To the best of our knowledge, this is the first work that synthesizes and critically evaluates existing evidence on the possible association between human gut microbiota and cognitive function in the elderly. For this purpose, comprehensive literature searches were conducted using the electronic databases PubMed, Google Scholar, and ScienceDirect. The gut microbiota of cognitively healthy and impaired elderly people may differ in the diversity and abundance of individual taxes, but specific taxes cannot be identified. However, some tendencies to changing the Firmicutes/Bacteroidetes ratio can be identified. Currently, clinical trials involving probiotics, prebiotics, and synbiotics supplementation have shown that there are premises for the claim that these factors can improve cognitive functions, however there is no single intervention beneficial to the elderly population. More reliable evidence from large-scale, long-period RCT is needed. Despite proposing several potential mechanisms of the gut microbiota's influence on the cognitive function impairment, prospective research on this topic is extremely difficult to conduct due to numerous confounding factors that may affect the gut microbiota. Heterogeneity of research outcomes impairs insight into these relations.
\end{abstract}

Keywords: gut microbiota; microbiome; cognitive function; cognitive impairment; probiotics; the elderly

\section{Introduction}

Aging is one of the inevitable and progressive biological processes that leads to irreversible physiological and functional changes throughout the body. Undoubtedly, aging is associated with the deterioration of the body's condition over the years. The functions of many organs and systems weaken. At the same time, the body's ability to withstand physiological burdens, fight infection, and maintain homeostasis decreases [1,2]. The aging process also leads to changes in the nervous system and the brain, and thus also to changes in cognitive functioning. Brain aging can go in one of three directions: successful aging - which proceeds without changes in the cognitive function, normal aging-when there is a slight deterioration of cognitive functions with age, and cognitive aging-including mild cognitive impairment and clinical cognitive disorders affecting everyday functioning [3]. Dementia is a general term used to describe a clinical syndrome characterized by progressive decline in cognitive domains, including memory, language, executive and visuospatial function, behavior, and ability to perform activities of daily living. The most common cause of dementia is Alzheimer's disease (AD), but the term includes also other forms such as vascular dementia, frontotemporal dementia, dementia with Lewy bodies, or even mixed forms. AD is an progressive and irreversible neurodegenerative disease 
and accounts for $60-80 \%$ of dementia cases [4]. Cognitive deficits between normal aging and dementia disorders are collectively called mild cognitive impairment (MCI), often considered an early stage of $\mathrm{AD}$, but resulted from a variety of etiologies [5]. Cognitive impairment related to dementia affects not only the everyday functioning and quality of life of elderly individuals, but it also exerts immense social and economic impacts. Therefore, identifying interventions to prevent or reduce the risk of its onset is an urgent public health priority [6].

The human microbiota can be defined as complex microbial community which exceeds the number of cells of the host [7]. A human microbiome consists of more than 30 trillion microorganisms per person, including bacteria, fungi, and viruses. It is estimated that the human microbiome accounts for $1-3 \%$ of one's body weight [8]. There is an excellent interpersonal variety in the microbiome composition, which is due to various factors like age, diet, socioeconomic status, medication, and many others, some still to be discovered $[9,10]$. It is said that the gastrointestinal microbiome-gut microbiota-is a dynamic and functional interface between the external environment and the human body [11]. Gut microbiota is composed of several species of microorganisms, including bacteria, archaea, yeast, and viruses. The predominant gut microbial phyla typical for a healthy human are Firmicutes, Bacteroidetes, Actinobacteria, Proteobacteria, Fusobacteria, and Verrucomicrobia, with the two phyla Firmicutes and Bacteroidetes representing 90\% of gut microbiota [12]. The Firmicutes phylum is composed of more than 200 different genera such as Lactobacillus, Bacillus, Clostridium, Enterococcus, and Ruminicoccus. Clostridium genera represent $95 \%$ of the Firmicutes phyla. Bacteroidetes consist of predominant genera such as Bacteroides and Prevotella. The Actinobacteria phylum is proportionally less abundant and mainly represented by the Bifidobacterium genus [13]. Several changes during aging were observed in gut microbiota diversity and among core species, which may affect human health [14].

Both cognitive functioning and the microbiome are influenced by many modifiable and non-modifiable factors, including lifestyle and diet [11,15-18]. It is considered that changes in the composition and proportions of the gut microbiota may be associated with numerous diseases; however, it should be emphasized that it is currently at an early stage of research. Despite proposing several potential mechanisms of the gut microbiota's influence on the development of diseases, prospective research on this topic is extremely difficult to conduct due to numerous confounding factors that may affect the gut microbiota [19].

The work presents a review of the data on the association between human gut microbiota and cognitive function in the elderly in accordance with recently published investigations. Despite increased interest in this area in recent years, there is a lack of original research concerning the elderly. To the best of our knowledge, this is the first review on gut microbiota and nutritional interventions in the context of cognitive decline in the elderly. We asked ourselves what has been confirmed in this regard so far. For this purpose, we have identified three indirect questions: Are there any differences in the gut microbiota between healthy elderly and those with cognitive impairment such as mild cognitive impairment (MCI), dementia, and $\mathrm{AD}$ ? Can nutritional factors improve cognitive functions in the elderly due to gut microbiota modulation? What are the possible mechanisms behind gut microbiota and cognitive impairment?

\section{Review Methodology}

The review methodology can be divided into several phases (Figure 1). In the first review phase, the planning phase, we identified research areas that could shed light on the review question. Several inquiry domains were deemed relevant, including research on the elderly with $\mathrm{MCI}$, dementia, and AD. 


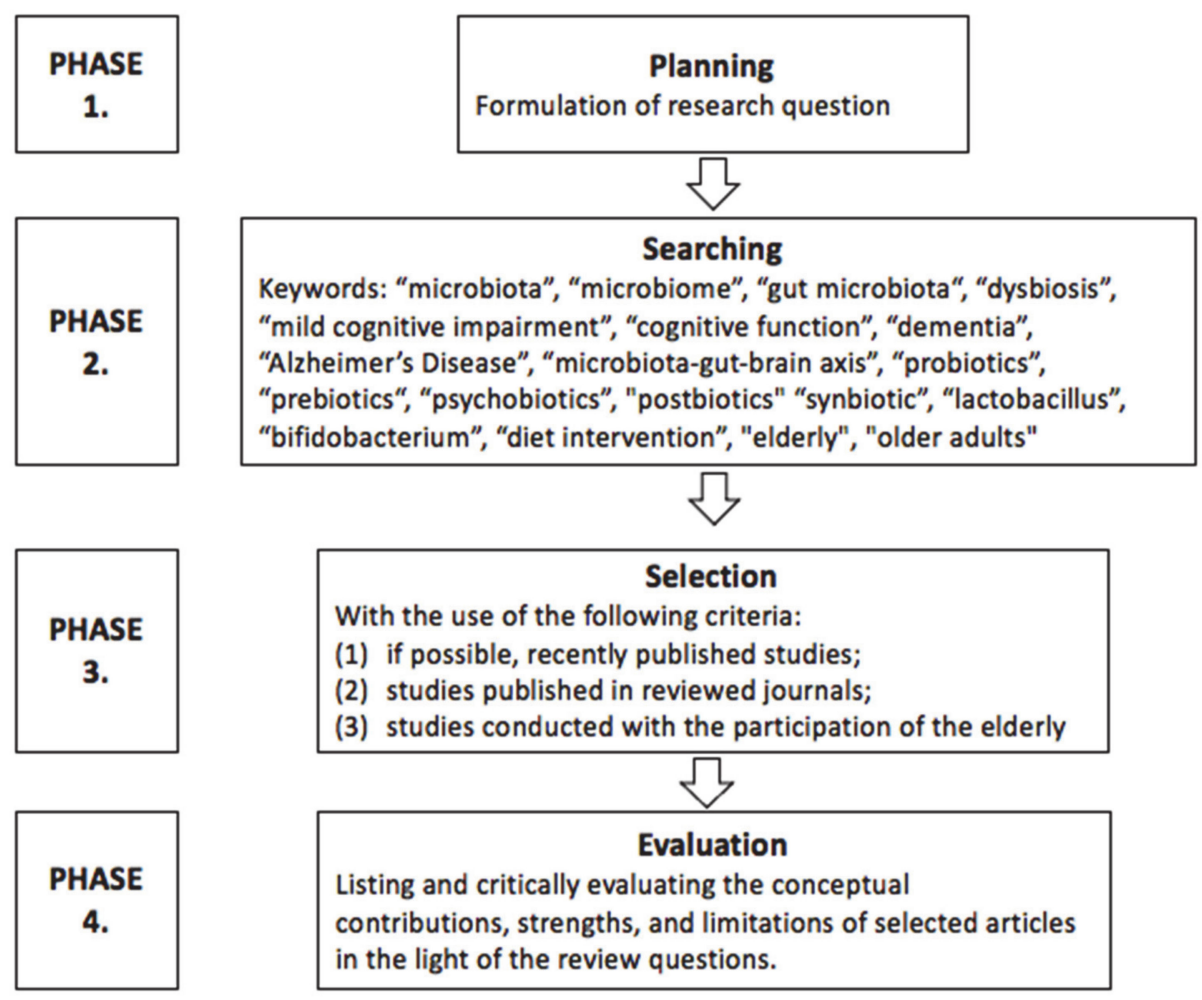

Figure 1. Diagram of review methodology.

The next phase of the review was the search for research and can be divided into two separate phases. In the first search phase, we used many keywords while looking for useful articles, among which were "microbiota", "microbiome", "gut microbiota", "dysbiosis", "mild cognitive impairment", "cognitive function", "dementia", "Alzheimer's Disease", "microbiota-gut-brain axis", "elderly", and "older adults" ( $n=9560)$. In the searching process, we used many databases, including PubMed, Google Scholar, ScienceDirect, Scopus, as well as Cochrane. Three authors did the research independently to avoid the omission of essential studies in this field. In the second search phase, we deepened our search for intervention proposed to modify gut microbiota that improves cognitive functions in the elderly, and for this purpose, new keywords were used, such as "probiotics", "prebiotics", "psychobiotics", "postbiotics", "synbiotic", “lactobacillus", "bifidobacterium”, and "diet intervention" ( $n=2724)$.

In the selection phase, titles and abstracts of articles retrieved during the search phase were screened, and relevant articles were selected. When selecting the publications, we were guided by the following criteria: (1) if possible, recently published studies; (2) studies published in reviewed journals; and (3) studies conducted with the participation of the elderly.

In the evaluation phase, the conceptual contributions, strengths, and limitations of selected articles were noted and critically evaluated in light of the review questions. This phase included studies concerning microbiome composition in cognition impairment $(n=6)$ and randomized controlled trials (RCT) studies concerning probiotic, prebiotic, and synbiotic intervention on cognition function $(n=12)$. It was relevant for this review to present the research results in a broad perspective, taking into account several larger issues (review of observational and interventional studies, the relationship between diet, the microbiome and cognitive disorders in the elderly, physiological mechanisms), but due to the small number of original studies and their heterogeneity, it was not possible to provide a systematic review. We aimed to provide a comprehensive view, showing the current state of knowledge, point out the errors and gaps, and the advancement of the research. 
Due to the complexity of the analyzed issue and a great variety of terms, we provided a glossary of frequently used terms (Table 1).

Table 1. Glossary of terms.

\begin{tabular}{ll}
\hline Terms & Definitions \\
\hline "Dysbiosis" & $\begin{array}{l}\text { is defined as a loss of beneficial microbes, expansion of pathobionts or } \\
\text { potentially harmful microorganisms, and a loss of microbial diversity [20]. }\end{array}$ \\
\hline "Microbiota" & $\begin{array}{l}\text { is defined as the microbial taxon (bacteria, archaea, or lower eukaryotes) } \\
\text { associated with humans health and disease [7]. }\end{array}$ \\
\hline "Microbiome" & $\begin{array}{l}\text { is defined as the catalog of microorganisms, their genomes, and the } \\
\text { surrounding environmental condition [7], but we are lacking a clear } \\
\text { commonly agreed definition [21]. }\end{array}$ \\
\hline "Postbiotics" & $\begin{array}{l}\text { are defined as "preparation of inanimate microorganisms and/or their } \\
\text { knownonents that confers a health benefit on the host" [22] they are also } \\
\text { "inactivated probiotics", they have also ability to deliver health benefits if } \\
\text { consumed with prebiotics or foods throughout their shelf life [23]. }\end{array}$ \\
\hline "Prebiotics" & $\begin{array}{l}\text { defined as "a selectively fermented ingredient that allows specific changes, } \\
\text { both in the composition and/or activity in the gastrointestinal microflora } \\
\text { that confers benefits upon host wellbeing and health" [24]. }\end{array}$ \\
\hline "Probiotics" & $\begin{array}{l}\text { are defined as "live microorganisms which when administered in adequate } \\
\text { amounts confer a health benefit on the host" [25]. }\end{array}$ \\
\hline "Psychobiotics" & $\begin{array}{l}\text { are defined as live bacteria which, when ingested in adequate amounts, } \\
\text { produces a mental health benefits [26]. }\end{array}$ \\
\hline & $\begin{array}{l}\text { contains combined both a probiotics and prebiotics that work synergistically } \\
\text { and have beneficially affect the host, and this effect is higher than that of the } \\
\text { probiotic alone [27]. }\end{array}$ \\
\hline
\end{tabular}

\section{How Does the Gut Microbiota Change with Aging?}

The microbiome composition differs even among healthy people, as there are multiple interindividual differences. The density and composition of the microbiota are affected by chemical, nutritional, and immunological gradients along the gut [11]. In the small intestine, there are typically high levels of acids, oxygen, and antimicrobials, and a short transit time, which is why it is mainly colonized by facultative anaerobes like Proteobacteria and Lactobacillales, but in the more distal area, gut microbiota becomes more diverse and approaches that of the colon [8]. Although to remain healthy, not only abundance, but also the microbiome's diversity, seem crucial, some examples of bacteria classification are potentially beneficial (Bifidobacterium, Lactobacillus, Eubacterium, and Fusobacterium) and potentially harmful (Staphylococcus, some of Clostridia and Proteus). Pathogenic bacteria do not occur extensively in a healthy human microbiota [28]. However, most of the gut microbes were mainly commensals (normal microbiota), which play a pivotal role in human health modulation, e.g., immune function, metabolic function, as well as neurobehavioural traits [14]. A decline in gut microbiota diversity is one of the most common changes during the aging process. Core species tend to decrease with the increased abundance of subdominant species [29]. The numbers of Firmicutes, Faecalibacterium prausnitzii, and Clostridium are significantly reduced in people $\geq 65$ years old [30]. Researchers also report a significant reduction of Lactobacillus and Bifidobacterium, which is related to lower levels of its metabolites: short-chain fatty acids (SCFAs) and $\gamma$-aminobutyric acid (GABA), which play an essential role in the nervous system, for example, in the regulation of neurotransmitter secretion. The only one of the dominant species of Bifidobacterium genus found in old age is B. adolescentis, or phenotypically close B. angulatum and B. longum in comparison in adult microbiota, where 4-5 species of Bifidobacterium are present [31,32]. Other authors also reported decreased Bacteroides and Enterobacteriaceae levels in cente- 
narians compared to younger adults [33,34]. The increase of proteolytic bacteria, such as Fusobacteria, Propionibacteria, and Clostridia, was found in the intestinal microbiota of elderly people leading to the development of putrefactive processes, especially in patients with post-antibiotic therapy. Furthermore, an increased number of proinflammatory Enterobacteriaceae, Streptococcus, Staphylococcus, and yeast cells were found, which may be associated with an elevated level of serum antibodies to commensal microbiota, such as Escherichia coli and Enterococcus faecalis [32,35]. Population differences should also be considered while analyzing microbiota changing data because it also influences microbiome composition, as there are different environmental conditions, level of hygiene, eating habits, and many more factors [29]. There are also differences in the gut microbiota composition in different geographic regions of the world which is most often explained by the diversity in the eating habits-Bacteroides enterotype is more common in Western countries (with high fat and protein intake) while Prevotella enterotype is more abundant in non-Western countries with high fiber consumption. The population of Africa is characterized by a high gut microbiota diversity (dominated by Actinobacteria, Bacteroidetes, Firmicutes, Proteobacteria, and Spirochaetes), while Europeans and Americans gut microbiota is enriched in Firmicutes, Actinobacteria, Verrucomicrobia, and Bacteroidetes [36].

It is not clear whether it is the aging process that influences gut microbiota changes or a combination of various factors related to the elderly. Gut microbiota changes might be associated with a general deterioration of health, the occurrence of chronic diseases, multi-drug use, including antibiotics and non-steroidal anti-inflammatory drugs, but also with changing lifestyle habits [15]. For example, antibiotics are now considered in two ways in influencing gut microbiota in the pathogenesis of AD: on the one hand, overuse of antibiotics may lead to decreased diversity and cause dysbiosis, but on the other hand, there is also the possibility of the use of antibiotics as therapeutic manipulation of gut microbiota [37]. Older people often eat a monotonous diet as a result of losing a partner due to death or divorce and living alone, repeatedly giving up preparing wholesome meals due to a lack of motivation to cook every day [38]. Furthermore, problems with dentition lead to choosing only known products with a certain hardness and structure, and not using raw vegetables and fruits or nuts [39]. As mentioned above, changing nutritional habits are very often connected with malnutrition, which is present in $5-30 \%$ of communitydwelling older adults, with higher numbers reaching $60 \%$ in acute care settings [40,41]. Not only in the oral cavity, but also in further parts of the gastrointestinal tract, there are some important changes connected with aging, which may influence the gut microbiota composition: for example, the compliance of gastric and rectal is lowered, which results in prolonged oro-caecal and colonic transit time [15]. Older people often limit their physical activity due to mobility limitations, fear of injury, or lack of motivation [42,43]. All of these factors can indirectly influence the composition and diversity of the gut microbiota and therefore affects human health [44-46].

\section{Gut Microbiota in Cognitive Disorders-Is There a Difference?}

The evidence regarding gut microbiota differences in patients with various kinds of cognitive decline is insufficient to perform a deep analysis and draw unequivocal conclusions. We found only single studies that compared the composition and abundance of the gut microbiota in healthy older people and people with cognitive impairment- the results are shown in Table 2 and the methodological details are presented in Table 3. 
Table 2. Changes in gut microbiota composition in various forms of cognitive impairment.

\begin{tabular}{|c|c|c|c|c|c|c|c|c|c|}
\hline \multirow{2}{*}{ Phyla } & \multirow{2}{*}{ Class } & \multirow{2}{*}{ Order } & \multirow{2}{*}{ Family } & \multirow[b]{2}{*}{ Genus } & \multirow{2}{*}{ Species } & \multicolumn{3}{|c|}{ Cognition } & \multirow{2}{*}{ References } \\
\hline & & & & & & MCI & D & AD & \\
\hline \multirow{13}{*}{ Firmicutes } & \multirow{8}{*}{ Clostridia } & \multirow{3}{*}{ Clostridiales } & & & & & & $\downarrow$ & [52] \\
\hline & & & \multirow{2}{*}{ Clostridiaceae } & & & $\downarrow$ & & $\downarrow$ & [52] \\
\hline & & & & Clostridium & & & & $\downarrow$ & [49] \\
\hline & & \multirow{5}{*}{ Eubacteriales } & \multirow{2}{*}{ Ruminococcaceae } & & & & & $\downarrow$ & $\begin{array}{l}{[52]} \\
{[49]}\end{array}$ \\
\hline & & & & Ruminococcus & & & & $\downarrow$ & [52] \\
\hline & & & \multirow{2}{*}{ Lachnospiraceae } & - & $\begin{array}{l}\text { Lachnospiraceae } \\
\text { bacterium NK4A136 }\end{array}$ & $\downarrow$ & $\downarrow$ & $\downarrow$ & $\begin{array}{l}{[52]} \\
{[51]}\end{array}$ \\
\hline & & & & Blautia & & $\downarrow$ & & $\begin{array}{l}\downarrow \\
\uparrow\end{array}$ & $\begin{array}{l}{[52]} \\
{[49]}\end{array}$ \\
\hline & & & Eubacteriaceae & Eubacterium & E. rectale & & $\downarrow$ & $\begin{array}{l}\uparrow \\
\uparrow\end{array}$ & $\begin{array}{l}51] \\
{[50]}\end{array}$ \\
\hline & Erysipelotrichia & Erysipelotrichales & Turicibacteraceae & Turicibacter & & & & $\downarrow$ & [49] \\
\hline & \multirow{3}{*}{ Negativicutes } & \multirow{2}{*}{ Veillonellales } & \multirow{2}{*}{ Veillonellaceae } & & & $\uparrow$ & & & [52] \\
\hline & & & & Dialister & & & & $\downarrow$ & [49] \\
\hline & & Selenomonadales & Acidaminococcaceae & Phascolarctobacterium & & & & $\uparrow$ & [49] \\
\hline & Bacilli & Staphylococcales & Gemellaceae & Gemella & & & & $\uparrow$ & [49] \\
\hline \multirow{4}{*}{ Bacteroidetes } & \multirow{4}{*}{ Bacteroidia } & \multirow{4}{*}{ Bacteroidales } & \multirow{3}{*}{ Bacteroidaceae } & & & $\begin{array}{l}+\uparrow \\
\uparrow\end{array}$ & & & $\begin{array}{l}{[52]} \\
{[49]}\end{array}$ \\
\hline & & & & Bacteroides & & $\uparrow$ & $\downarrow$ & $\begin{array}{l}\uparrow \\
\uparrow \\
\uparrow\end{array}$ & $\begin{array}{l}{[47]} \\
{[48]} \\
{[49]} \\
{[52]}\end{array}$ \\
\hline & & & & & B. fragilis & & & $\downarrow$ & [50] \\
\hline & & & Rikenellaceae & Alistipes & & & & $\uparrow$ & [49] \\
\hline \multirow{2}{*}{ Actinobacteria } & Actinomycetia & Bifidobacteriales & Bifidobacteriaceae & Bifidobacterium & & & $\uparrow$ & $\downarrow$ & $\begin{array}{l}{[47]} \\
{[49]}\end{array}$ \\
\hline & Coriobacteriia & Eggerthellales & Eggerthellaceae & Adlercreutzia & & & & $\downarrow$ & [49] \\
\hline \multirow{3}{*}{ Proteobacteria } & \multirow{2}{*}{ Gammaproteobacteria } & \multirow{2}{*}{ Enterobacteriales } & \multirow{2}{*}{ Enterobacteriaceae } & & & & & $\uparrow$ & [52] \\
\hline & & & & Escherichia/Shigella & & & & $\uparrow$ & [50] \\
\hline & Deltaproteobacteria & Desulfovibrionales & Desulfovibrionaceae & Bilophila & & & & $\uparrow$ & [49] \\
\hline
\end{tabular}


Table 3. Methodological issues of studies about microbiome composition in cognition impairment—case controls.

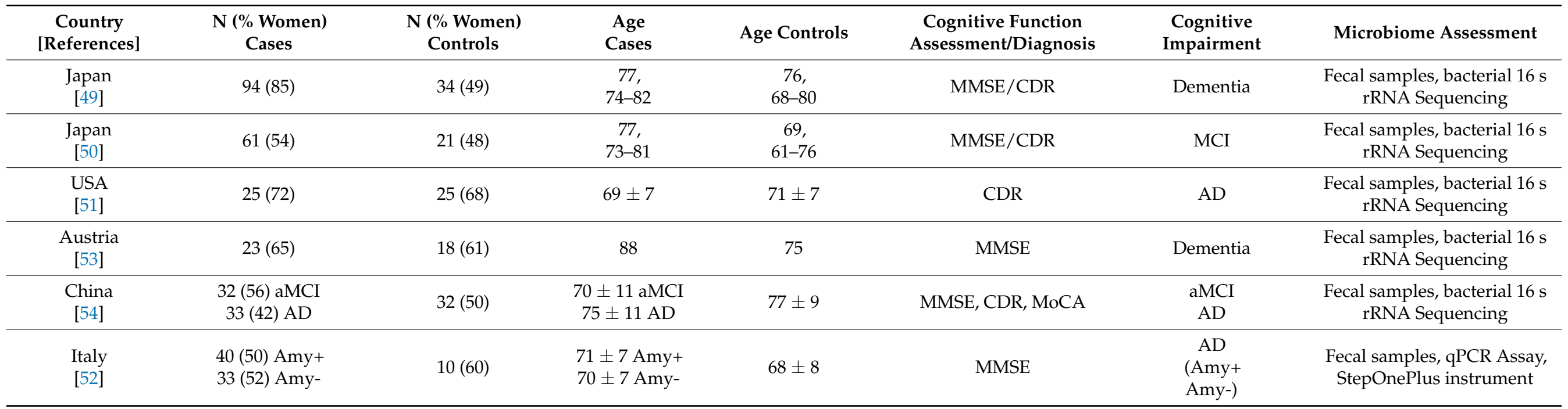

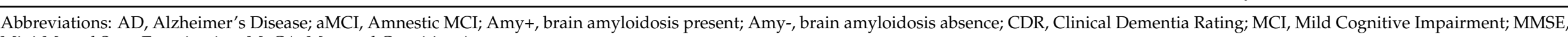
Mini-Mental State Examination; MoCA, Montreal Cognitive Assessment. 
Saji et al. studied 128 patients of a memory clinic, of which 94 were classified as nondemented and 34 as demented based on the Mini-Mental State Examination (MMSE) score and Clinical Dementia Rating Score. The authors showed a significantly lower percentage of Bacteroides in the dementia group than non-dementia and slightly, non-statistically significantly more frequent Lactobacillus and Bifidobacterium in the dementia group, which was unexpected because of its pro-health properties [47,48]. Another surprising result was that the Firmicutes/Bacteroidetes ratio was significantly higher in the dementia group. Components of the gut microbiota were independently associated with dementia, even more strongly than traditional dementia biomarkers. However, it should be pointed out that the authors included patients with mild cognitive decline in the non-demented group, which might have influenced the results [49]. The authors also provided another analysis with the participation of some patients from the previously described study, but this time they excluded patients with dementia and divided the 82 remaining patients into two groups: mild cognitive decline (MCI) and cognitively healthy group. Patients with MCI had a higher prevalence of Bacteroides; a multivariable logistic regression analysis showed that a greater prevalence of this genus was independently associated with MCI. However, these two studies are of cross-sectional design, so it is impossible to conclude about causeand-effect dependencies. It should also be underlined that these results were only obtained in a relatively small sample of the Japanese population, and there is a great need to conduct further research on different and more representative populations [50].

Decreased gut microbiota diversity and changes in its composition, including decreased Firmicutes, increased Bacteroidetes, and decreased Bifidobacterium in patients with $\mathrm{AD}$, were found in a study conducted with the participation of $25 \mathrm{AD}$ and 94 nondemented people from the American population [51]. Furthermore, researchers from Italy, in their study that included 83 patients ( 10 cognitively healthy amyloid negative controls, 40 cognitively impaired amyloid positive, and 33 cognitively impaired amyloid-negative), showed that patients with cognitive impairment and amyloidosis had a lower abundance of anti-inflammatory taxa Eubacterium rectale and higher levels of the proinflammatory taxes Escherichia/Shigella in gut microbiota [52]. Similar results concerning lower counts of Eubacterium rectale in demented patients have recently been obtained in the Austrian population [53]. The authors also noted a significantly lower abundance of uncultured Lachnospiraceae sp. and Lachnospiraceae NK4A136 in the group of 23 demented patients, which was also proved in the group of AD patients and patients with amnestic MCI when compared to healthy controls. The authors provided an extensive analysis on different classes and families of gut microbiota and revealed many statistically significant differences in the gut microbiota composition in patients with $\mathrm{AD}$ and healthy controls (detailed results are presented in Table 2) [54].

In contrast, no significant differences in microbiome diversity were shown in mildly cognitively impaired subjects compared to cognitively healthy subjects in a small group of 17 patients (11 MCI vs. cognitively healthy) [55]. However, the authors detected several unique microbial signatures in subjects with MCI.

Recently, scientific evidence highlighted the role of oral microbiota in influencing brain functions. Numerous studies have shown that periodontal issues are also associated with neurodegenerative and cognitive decline [56-58]. It was found that Porphyromonas gingivalis, a bacterium associated with periodontitis, has been implicated in dementia. It has been also suggested that the bacteria is capable of modulating the gut microbiota [59].

In summary, small-sample studies have shown that the gut microbiota of cognitively healthy and impaired elderly people may differ in the diversity and abundance of individual taxes, but due to the small number of studies and divergent results, specific taxes cannot be clearly identified. However, some tendencies to changing the Firmicutes/Bacteroidetes ratio can be identified. Gut microbiota diversity seems to be one of the crucial factors in retaining a healthy microbiome in older age; however, its assessment is connected with multiple methodological issues. 


\section{Is There a Link Between Diet, Cognitive Function, and Gut Microbiota in the Elderly?}

Available reports on the existing differences in the composition and diversity of gut microbiota, which depend on cognitive functioning, give rise to the question of whether it is possible to manipulate the gut microbiota to improve cognitive functions or to reduce the risk of cognitive impairment in the elderly. Multiple environmental and host factors play an important role in shaping gut microbiota composition and function. Within environmental factors, diet is considered as a key factor [60], both as short-term changes [61], as well as long-term dietary patterns and habitual intake [62]. Due to the lack of long-term human studies, it cannot be determined whether prolonged dietary changes can induce permanent alterations in the gut microbiota, but it is possible that habitual diets have a greater influence than acute dietary changes [63].

Several popular diets, including the Western, vegetarian, vegan, ketogenic diet, and elimination diets such as low-FODMAP and gluten-free diet, have been studied for their ability to modulate the gut microbiota diversity [45,64]. The Mediterranean Diet is one of the most discussed nutritional models in the literature in the context of cognitive enhancement. This diet is considered one of the healthiest in the world because of its documented association with reduced morbidity and mortality due to many chronic diseases [65]. Studies showed that adherence to the Mediterranean diet is associated with a reduced risk of stroke, depression, and cognitive impairment [66]. This is also confirmed by the metaanalysis of prospective studies by [67] Singh et al., which showed that people who adhere to the Mediterranean diet, to a greater extent, had a lower risk of MCI and AD, as well as the progression of MCI to dementia [67]. Moreover, studies have observed a beneficial effect of the Mediterranean diet on the cognitive functioning of healthy elderly people [68]. Recent data demonstrate that adherence to the Mediterranean diet promotes changes in the gut microbiota diversity and richness, by increasing Bacteroidetes and Firmicutes, changing the ratio of Bacteroidetes/Firmicutes, and increasing total levels of fecal SCFAs [69-71]. However, only a few studies have evaluated the correlation between the three variables: dietary patterns, gut microbiota, and cognitive function in older adults. Adherence to the Mediterranean diet for 12 months was associated with specific microbiome alterations in 612 elderly subjects. Taxa along with adherence to the diet were positively associated with several markers of lower frailty and improved cognitive function, and negatively associated with inflammatory markers including C-reactive protein and interleukin-17 [72]. A randomized, double-blind, crossover, single-center pilot study of Mediterranean-ketogenic diet (MMKD) six-week intervention on 17 elderly subjects (11 MCI and six cognitively normal) suggested that MMKD can modulate the gut microbiome, SCFAs level, and AD biomarkers in cerebrospinal fluid, including the deposition of $\beta$-amyloid (A $\beta)-40$ and A $\beta-42$ [55].

Some nutrients have been shown to affect the composition of the gut microbiota as well as cognitive function (Table 4). For example, omega-3, polyphenols, and vitamin D appear to have the potential to confer health benefits via modulation of the gut microbiota [45]. A little more is known about the impact of nutrients on cognitive function than the gut microbiota in the elderly. Observational studies indicate the role of poor nutritional status (e.g., low vitamin D status, low plasma level of antioxidant) in poorer cognition and an increased risk of cognitive impairment, but RCT studies do not confirm that the use of dietary supplements can help maintain cognitive health. The RCT studies showed that fiber and vitamin D influence the composition of the intestinal microbiome. Both, in the case of cognitive function and gut microbiota, the adverse effect is noted for saturated fatty acids. However, to the best of our knowledge, there are no clinical trials that would link nutrients, gut microbiota, and cognitive functions. In this review, we focus only on probiotic interventions in the elderly and their effects on cognition by modifying the gut microbiota. 


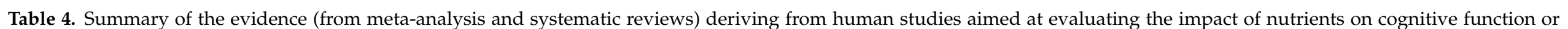
gut microbiota.

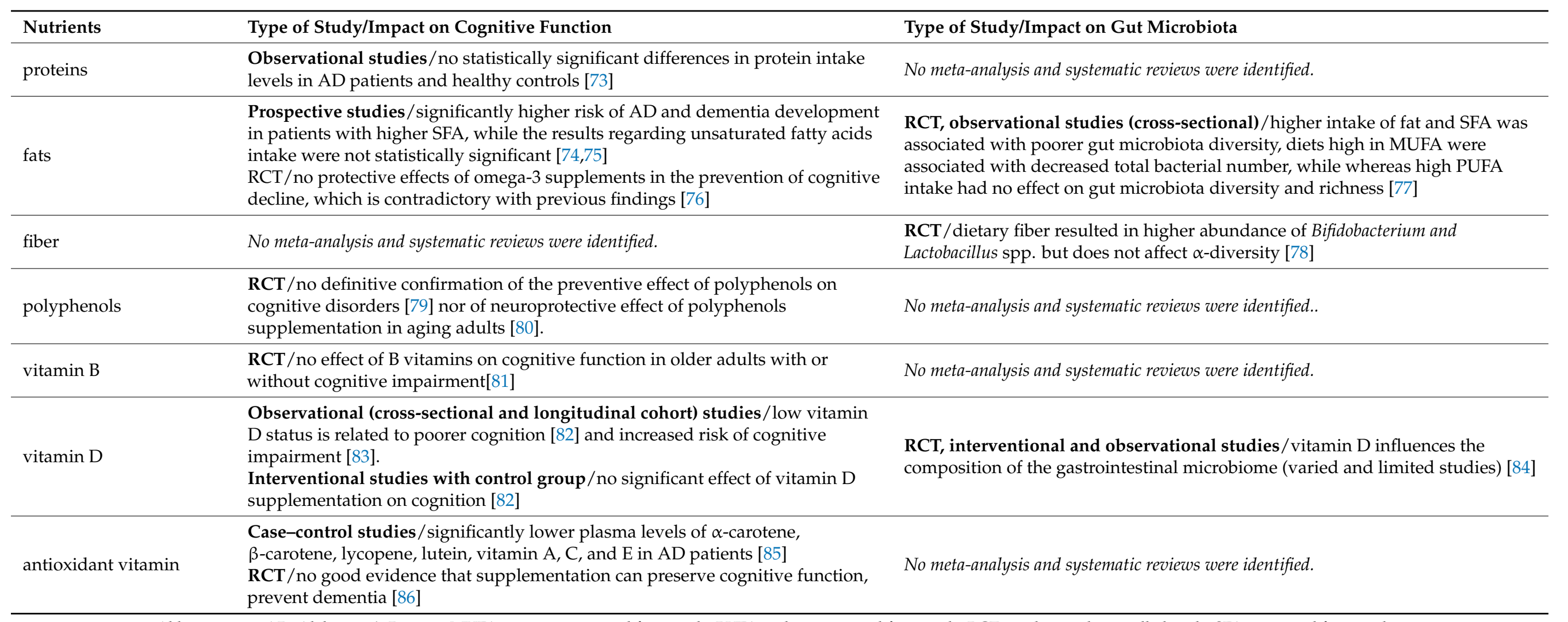

Abbreviations: AD, Alzheimer's Disease; MUFA, monounsaturated fatty acids; PUFA, polyunsaturated fatty acids; RCT, randomized controlled trials; SFA, saturated fatty acids. 


\section{Can Administering Probiotic or Prebiotics Supplementation Improve Cognitive Functions in the Elderly?}

It has been noted that the elderly buy probiotic supplementation expecting to improve their health [87]; however, probiotic effects on the cognitive function in this particular group have not been studied well. The "psychobiotics" theory indicates that probiotics have a potential, positive effect on mental health, but more research on this relation is warranted [88]. The health effects of microbiota-driven therapy (pre-, pro-, and synbiotics) on the elderly include changes in the composition and activity of the intestinal microbiota, especially by promoting the growth of bifidobacteria and lactobacilli [89]. However, it should be emphasized that only limited studies were conducted specifically on the elderly.

The results of the meta-analysis by Lv et al. showed that probiotics supplementation enhanced cognitive function in human and animal studies, and the effects on cognitively impaired individuals were greater than those on healthy ones. Moreover, the authors showed that a duration of less than 12 weeks and a single strain of probiotics were more effective in human studies. This meta-analysis included seven human studies, where three studies included subjects diagnosed with AD, one with healthy elderly, and three with cognitive impairment participants (fibromyalgia, major depressive disorder, minimal hepatic encephalopathy) where the average age was under 60 years old [90].

To the best of our knowledge, only a few studies have assessed this effect both among healthy elderly and those with cognitive impairment. The methodological details of the discussed studies are presented in Table 5 . The studies with healthy older adults give different results. The lack of beneficial effect in cognitively healthy subjects was noted in the study by Benton et al., which unexpectedly showed that after 21 days of ingestion of a probiotic milk drink containing $L$. casei Shirota or placebo, memory abilities were slightly worse in the probiotic group [91]. On the other hand, other studies involving healthy individuals indicate potentially beneficial effects of probiotics. The administration of Lactobacillus helveticus - fermented milk drink-for 8 weeks in middle-aged healthy adults [92] and 12 weeks in healthy elderly people [93] improved the cognitive function compared to the placebo group. Moreover, Kim et al. demonstrated that probiotics (Bifidobacterium bifidum BGN4 and Bifidobacterium longum BORI) consumed for 12 weeks improved cognitive and mental health as well as changed the gut microbiota composition in healthy community-dwelling elderly [94]. Inoue et al. demonstrated that combined probiotic bifidobacteria supplementation and moderate resistance training may improve the mental condition, body weight, and bowel movement frequency in healthy elderly subjects [95].

The results of studies involving participants with cognitive impairment are the subject of several meta-analyses. Den et al. indicated that probiotics significantly improved cognitive performance in $\mathrm{AD}$ and MCI patients (SMD $=0.37 ; 95 \% \mathrm{CI}, 0.14$ to 0.61 ). This metaanalysis included five randomized controlled trials (RCT), where three studies included subjects diagnosed with $\mathrm{AD}$ and two with $\mathrm{MCI}$ [96]. However, another meta-analysis, which included the same data but considered only individuals with AD (3 RCT), showed no beneficial effect of probiotic supplementation on cognitive function (SMD $=0.56$; $95 \% \mathrm{CI}$ : -0.06 to 1.18$)$ [97]. 
Table 5. Methodological issues of randomized controlled trials (RCT) studies about probiotic, prebiotic, and synbiotic intervention on cognition function.

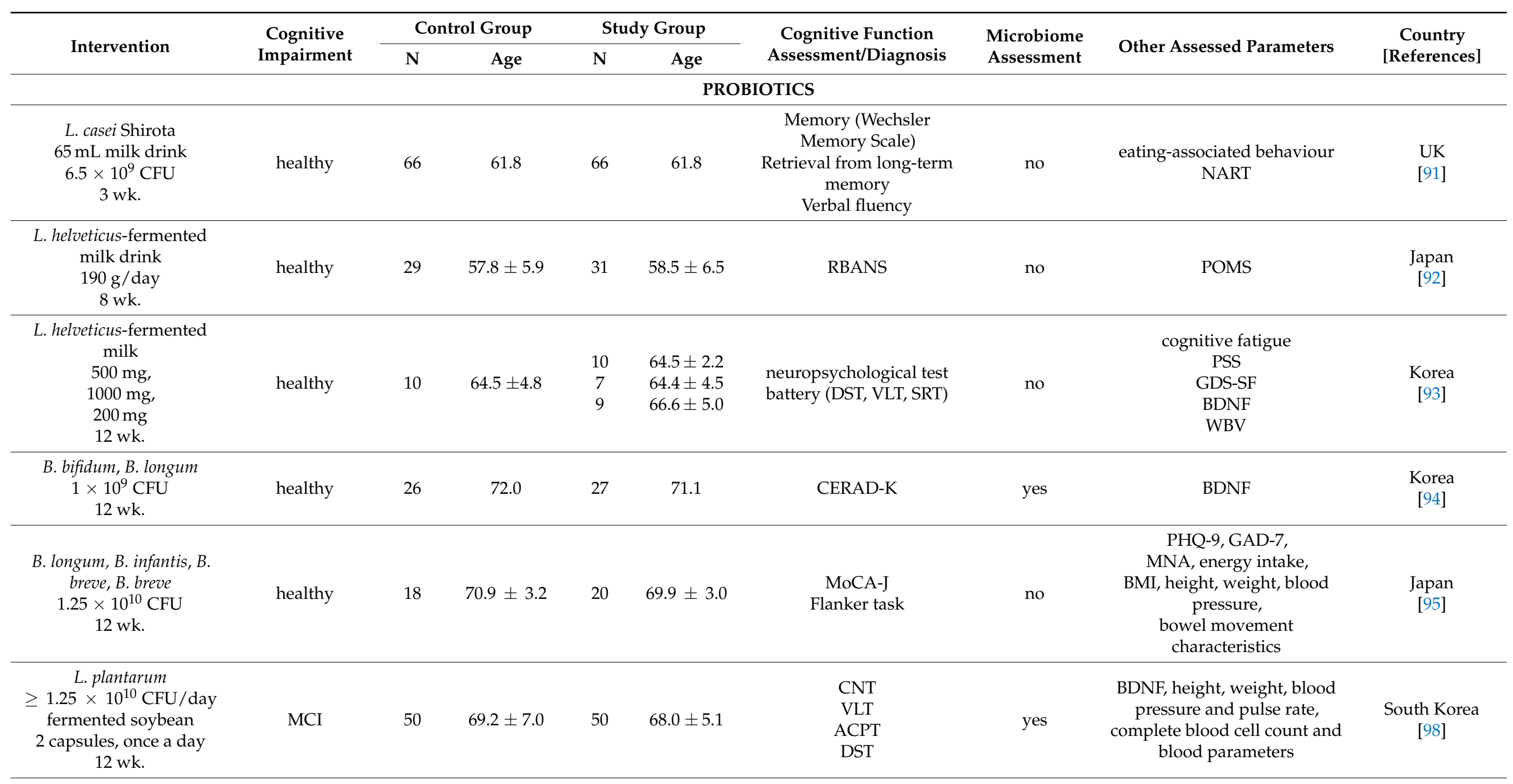


Table 5. Cont.

\begin{tabular}{|c|c|c|c|c|c|c|c|c|c|}
\hline \multirow{2}{*}{ Intervention } & \multirow{2}{*}{$\begin{array}{l}\text { Cognitive } \\
\text { Impairment }\end{array}$} & \multicolumn{2}{|c|}{ Control Group } & \multicolumn{2}{|c|}{ Study Group } & \multirow{2}{*}{$\begin{array}{l}\text { Cognitive Function } \\
\text { Assessment/Diagnosis }\end{array}$} & \multirow{2}{*}{$\begin{array}{l}\text { Microbiome } \\
\text { Assessment }\end{array}$} & \multirow{2}{*}{ Other Assessed Parameters } & \multirow{2}{*}{$\begin{array}{c}\text { Country } \\
\text { [References }\end{array}$} \\
\hline & & $\mathbf{N}$ & Age & $\mathbf{N}$ & Age & & & & \\
\hline $\begin{array}{c}\text { B. breve } \\
>1.0 \times 10^{10} \mathrm{CFU} / \text { day } \\
2 \text { capsules } \\
12 \mathrm{wk} .\end{array}$ & MCI & 60 & $61.6 \pm 6.4$ & 61 & $61.5 \pm 6.8$ & $\begin{array}{l}\text { MMSE } \\
\text { RBANS }\end{array}$ & no & $\begin{array}{c}\text { hs-CRP } \\
\text { haematological and biological } \\
\text { blood parameters }\end{array}$ & $\begin{array}{c}\text { Japan } \\
\text { [99] }\end{array}$ \\
\hline $\begin{array}{c}\text { L. fermentum, L. plantarum, } \\
\text { L. acidophilus, B. lactis, B. } \\
\text { longum, B. bifidum } \\
3 \times 10^{9} \mathrm{CFU} / \mathrm{g} \text { of each } \\
2 \text { capsules, once a day } \\
12 \mathrm{wk} .\end{array}$ & $\mathrm{AD}$ & 23 & $80.6 \pm 1.8$ & 25 & $79.7 \pm 1.7$ & TYM & no & $\begin{array}{c}\text { TAC, GSH, MDA, Il-6, Il-10, } \\
\text { TNF-a, NO, } 8-\mathrm{OHdG} \text {, weight, } \\
\text { BMI }\end{array}$ & $\begin{array}{l}\text { Iran } \\
{[100]}\end{array}$ \\
\hline $\begin{array}{c}\text { L. acidophilus, L. casei, } L \text {. } \\
\text { fermentum B. bifidum, } \\
2 \times 10^{9} \text { CFU/g of each } \\
200 \mathrm{~mL} \text { probiotic } \\
\text { milk/day } \\
12 \mathrm{wk} .\end{array}$ & $\mathrm{AD}$ & 30 & $82 \pm 1.7$ & 30 & $77.7 \pm 2.6$ & MMSE & no & $\begin{array}{c}\text { TAC, GSH, hs-CRP, MDA, NO, } \\
\text { HOMA-B, HOMA-IR, QUICK, } \\
\text { FPG, TG, TC, LDL, HDL, } \\
\text { VLDL, TC/HDL, } \\
\text { insulin, weight, BMI } \\
\text { dietary intakes (3-day food } \\
\text { records) }\end{array}$ & $\begin{array}{l}\text { Iran } \\
{[101]}\end{array}$ \\
\hline $\begin{array}{c}\text { L. acidophilus, B. bifidum, } \\
\text { B. longum } \\
2 \times 10^{9} \mathrm{CFU} / \mathrm{g} \text { each for } \\
\text { probiotic capsule }+ \\
\text { selenium } 200 \mathrm{ng} / \text { day } \\
12 \mathrm{wk} .\end{array}$ & $\mathrm{AD}$ & 52 & $78.8 \pm 10.2$ & 27 & $76.2 \pm 8.1$ & MMSE & no & $\begin{array}{c}\text { TAC, GSH, hsCRP, insulin, } \\
\text { HOMA-IR, QUICKI, TG, NO, } \\
\text { FPG, MDA, TC, LDL, VLDL, } \\
\text { HDL, TC/HDL, } \\
\text { Gene expression related to } \\
\text { inflammation, insulin and } \\
\text { lipid metabolism } \\
\text { BMI, weight, dietary intakes } \\
\text { (3-day food records) }\end{array}$ & $\begin{array}{l}\text { Iran } \\
{[102]}\end{array}$ \\
\hline
\end{tabular}


Table 5. Cont.

\begin{tabular}{|c|c|c|c|c|c|c|c|c|c|}
\hline \multirow{2}{*}{ Intervention } & \multirow{2}{*}{$\begin{array}{l}\text { Cognitive } \\
\text { Impairment }\end{array}$} & \multicolumn{2}{|c|}{ Control Group } & \multicolumn{2}{|c|}{ Study Group } & \multirow{2}{*}{$\begin{array}{l}\text { Cognitive Function } \\
\text { Assessment/Diagnosis }\end{array}$} & \multirow{2}{*}{$\begin{array}{l}\text { Microbiome } \\
\text { Assessment }\end{array}$} & \multirow{2}{*}{ Other Assessed Parameters } & \multirow{2}{*}{$\begin{array}{c}\text { Country } \\
{[\text { References }]}\end{array}$} \\
\hline & & $\mathbf{N}$ & Age & $\mathbf{N}$ & Age & & & & \\
\hline \multicolumn{10}{|c|}{ PREBIOTICS } \\
\hline $\begin{array}{c}\text { Darmocare Pre } \\
\text { (inulin }+ \\
\text { fructooligosaccharides) } \\
13 \mathrm{wk} .\end{array}$ & non-demented & 22 & $73.4 \pm 1.8$ & 28 & $74.2 \pm 1.6$ & MMSE & no & $\begin{array}{c}\text { Frailty } \\
\text { Functional Impairment } \\
\text { Sleep quality } \\
\text { Blood analysis and haemogram }\end{array}$ & $\begin{array}{l}\text { Spain } \\
\text { [103] }\end{array}$ \\
\hline \multicolumn{10}{|c|}{ SYNBIOTIC } \\
\hline $\begin{array}{c}\text { L. paracasei, L. ramnosus, } L \text {. } \\
\text { acidophilus, B. lactis } \\
\left(10^{8}-10^{9} \mathrm{CFU} \text { of each }\right) \\
+ \text { fructooligosaccharide } \\
\text { twice a day } \\
24 \mathrm{wk} .\end{array}$ & $\begin{array}{l}\text { apparently } \\
\text { healthy }\end{array}$ & 24 & $77.0 \pm 1.3$ & 25 & $67.9 \pm 4.5$ & MMSE & no & $\begin{array}{l}\text { GDS-15, } \% \text { of body fat, IL-6, } \\
\text { TNF- } \alpha, \text { IL-10, DAO, } \\
\text { IFABP, LPS }\end{array}$ & $\begin{array}{l}\text { Brazil } \\
{[104]}\end{array}$ \\
\hline
\end{tabular}

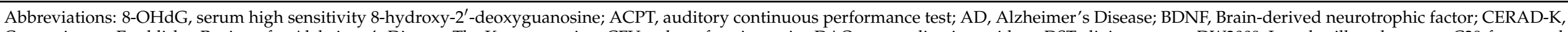

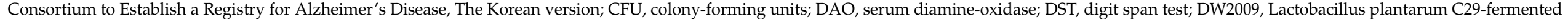

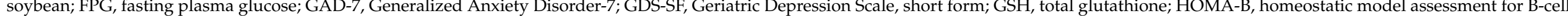

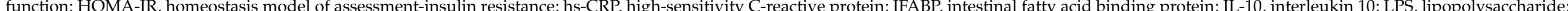
MCI Mild Cognitive Impairment; MDA, malondialdehyde; MMSE, Mini-Mental State Examination; MNA, Mini Nutritional Assessment; MoCA-J, Japanese version of the Montreal Cognitive Asse tumor necrosis factor $\alpha$; VLT, verbal learning test; WBV, frictional force of blood flow in vessels. 
The discrepancy in these meta-analyses results suggests that there is too few data for unequivocal conclusions to be drawn. It needs to be highlighted that the number of studies assessing the effect of the probiotic intervention on cognitive function in elderly people is limited. Many unknowns still require clarification, and many parameters need to be controlled both from the probiotic and host sides when planning studies. The illustration of this issues is presented in Figure 2.

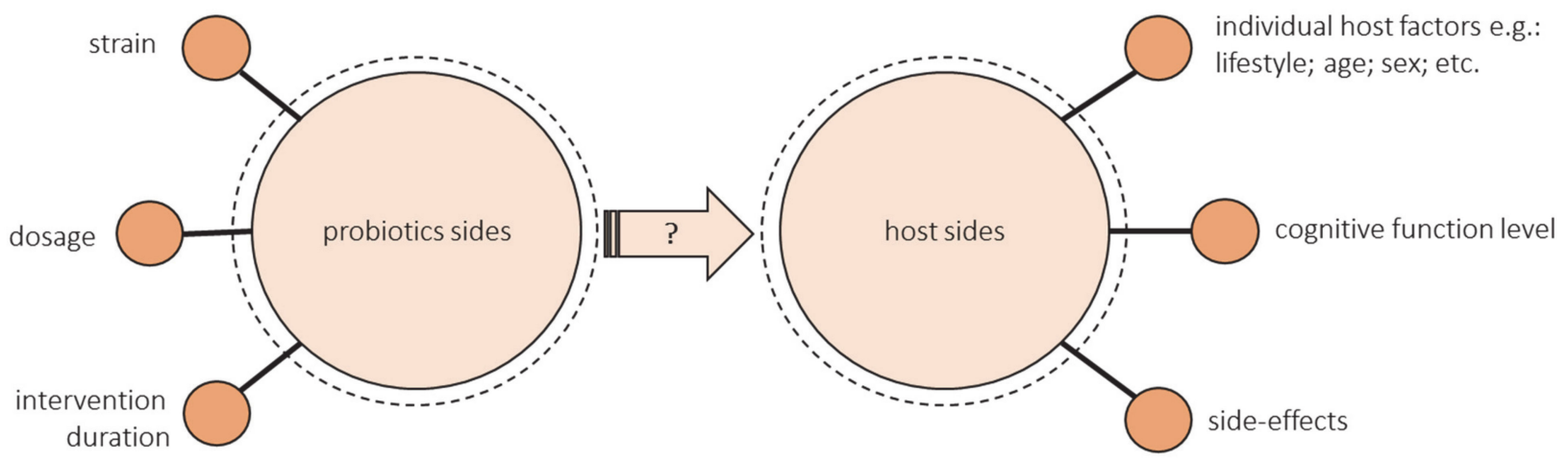

Figure 2. Unknowns that require clarification and parameters that need to be controlled from the probiotic and host sides in planning of intervention trials.

From the probiotic's side:

1. The health-promoting effect of a probiotic depends on the strain. Some strains show a positive effect on cognitive function, and some do not. The research uses either single strain or multiple strain probiotics. Lv et al. observed that a single strain of probiotics was more effective in human studies [90]. However, as previously mentioned, diversity may be crucial for the cognitive health of the elderly, but most studies have not assessed changes in the microbiota after administering probiotic supplementation.

2. There is not enough evidence to provide information on dose-response functions associated with probiotics. Most studies have not compared the different doses. Doses that ranged from $10^{8}$ to $10^{11}$ were used most often, but more reliable evidence from various dosages is needed, especially outside these common doses [96].

3. There are also many unknowns about the duration of probiotics ingestion. The most common intervention duration of the studies was 12 weeks. Some authors emphasize that the intervention could have been too short $[94,99]$. Lv et al. suggest that a duration of less than 12 weeks was more effective, but these studies included data from middle-aged adults [90]. There is a lack of long-term studies especially in the group of elderly.

From the host's side:

1. The success of the intervention could be modified by the hosts' diet and lifestyle, age, sex, geographic region, concomitant disease, antibiotic exposure, and baseline microbiota composition [105-107]. All these factors should be controlled. Still, the studies did not assess the effectiveness of probiotic intake through gut microbiota composition. Most studies did not consider the baseline gut microbiota characteristics of included individuals. Despite the influence of diet on the gut microbiome, the majority of studies contain little or no analysis of dietary intake. There is a need of conducting more well-controlled longitudinal studies and randomized controlled trials that may isolate the impact of specific changes in dietary intake on gut microbiota [108].

2. The level of cognitive functioning can make a difference. There are no studies that would compare people with different levels of cognitive functioning. Kobayashi found a beneficial effect of probiotics in the low-score subgroup but not in the high-score subgroup (indicating favorable cognitive performance), so they suggest comparing 
the results between MCI or early dementia and cognitively normal individuals [99]. Lv et al. showed that the effects of probiotics supplementation were greater in the case of cognitively impaired individuals than those on healthy ones, but they only included one study with cognitively healthy people [90]. What is more, the current RCT, including patients with cognitive impairment, are mainly focused on inflammatory and oxidative biomarkers rather than cognitive function, so they used MMSE or TYM, which are used for screening rather than cognitive assessment [100-102].

3. The side-effects of probiotics intervention should be considered alongside the observed benefits [109]. Hibberd et al. reported that Lactobacillus rhamnosus GG ATCC 53,103 (LGG) $\left(1 \times 10^{10} \mathrm{CFU}\right)$ is safe and well-tolerated in healthy adults aged 65 years and older [110]. Similarly, the results of Hwang et al. suggest that Lactobacillus plantarum C29-fermented soybean can be safely administered to enhance cognitive function in individuals with MCI. Adverse events observed were stomach aches, headaches, gastritis, erectile dysfunction, and seborrheic dermatitis, all of which were classified as a mild adverse event [98].

Only single RCT studies on the effects of prebiotics and synbiotics supplementation on cognition in the elderly are available (Table 5). Buigues et al. evaluated whether the regular intake of prebiotic can improve frailty criteria, functional status, and response of the immune system in elderly people affected by the frailty syndrome. They assessed the effect on functional and cognitive behavior as well as sleep quality, but no significant effects were observed [103], whereas Louzada and Ribeiro investigated the effect of a synbiotic on symptoms of brain disorders and inflammation in the elderly, and found weak effects of synbiotic on depressive symptoms and more optimistic effects on cognition in apparently healthy elderly [104].

\section{What Is the Link Between the Microbiota-Gut-Brain Axis and Cognitive Function?}

Recent studies have shown that the gut microbiota is involved in the neurodevelopment and diverse brain functions through regulating the gut-brain axis. The term "microbiota-gut-brain axis" (broadened from "gut-brain axis") [111] represents the bidirectional communication between the central nervous system $(\mathrm{CNS})$ and the gastrointestinal tract [111]. The communication between CNS and the enteric nervous system is multichannel and involves neural, immune, endocrine, and metabolic signaling mechanisms [112,113]. As we presented above, it is still discussed if dysbiosis of gut microbiota, as well as probiotics and prebiotic supplements, may influence cognitive function, especially since the mechanism underlying between the microbiota-gut-brain axis and cognitive function is not fully understood.

Human gut microbiota produces various metabolites that influence the nervous system directly like noradrenaline, serotonin, acetylcholine, SCFAs, and GABA produced by Lactobacillus and Bifidobacterium or dopamine produced by Escherichia and Bacillus. An essential feature of gut microbiota metabolites is modulating both microbe-microbe and microbe-host interactions, which all impact human health [8,45]. In terms of interbacterial communication, gut bacteria produce many signaling molecules, known as quorum sensors, which may influence apoptosis, growth, and bacterial homeostasis. Other metabolites influence multiple host processes via communication with the central nervous system (like GABA). Some gut microbiota components can produce vitamins necessary for proper immune functioning like $\mathrm{K}$ and $\mathrm{B}$ group vitamins [8,31].

In recent years, the number of studies that focus on explaining this mechanism has been increasing, but most of the research has been done within animal models. In a scoping review, Gao et al. distinguished five main pathways through which the microbiota-gutbrain axis may modify cognitive function [114]. First, gut microbiota dysbiosis has been shown to have an impact on the function of the hypothalamic-pituitary-adrenal (HPA) axis, which regulates cognitive function. The second pathway is the neuronal regulation pathway, where gut microbiota communicates with the CNS and autonomic nervous system (ANS) via vagus nerve stimulation $[114,115]$. The other pathway is based on 
microbiota and its metabolites that can stimulate the increased release of inflammatory markers, interacting with the blood-brain barrier. Fourth, the gut microbiota products, such as neurotransmitters or hormones, have been shown to modify CNS function. The last pathway that can explain gut microbiota's role in the regulation of cognitive function is its induction of modification of myelination, myelin plasticity, microRNA expression in the prefrontal cortex, which plays an important role in planning and decision making. As the authors suggest, the mechanism through which gut microbiota modifies cognitive function is still not well understood; it is likely a combination of presented mechanisms [114].

\section{What Are the Possible Mechanisms behind Gut Microbiota and Dementia?}

Although many pathways are considered in the link between gut microbiota and cognitive function, little is known about detailed mechanisms among the elderly with dementia. Knowledge about the physiopathology role of the gut microbiota is much more established in other neuropsychiatric disorders (e.g., Parkinson's disease) [116].

However, the pathomechanism of dementia remains not fully understood; the inflammatory process appears in most of the hypotheses as having a key role in cognitive decline. It is well established that aging is associated with inflammation [117], and this state is often referred to as "inflammaging" (chronic state of inflammation) [117]. Furthermore, as described previously, with aging, the diversity of the gut microbiome decreases, and recent studies have shown that gut microbiota may promote chronic inflammation [116]. In view that the main risk factor of dementia is aging, which is associated with the inflammation process, which in turn increases gut permeability, bacterial translocation, and others, it is hypothesized that the microbiota-gut-brain axis may explain the link between aging, dementia, and inflammation $[54,117]$.

Recent studies also indicate increasing attention to microbiome-associated metabolites, which could alone affect and modulate cognitive function, and thus dementia [118]. Saji et al. (2020) hypothesized that higher concentrations of fecal metabolites of the gut microbiome might be associated with the presence of dementia, independently of the other risk factors for dementia and dysregulation of the gut microbiome [118]. The authors indicated that the concentrations of such metabolites as ammonia, formic acid, iso-butyric acid, isvaleric acid, phenol, and p-cresol were significantly higher among patients with dementia compared to non-demented controls. Furthermore, each one standard deviation increment in the fecal ammonia concentration was associated with a 1.6-fold risk for the presence of dementia. This study even showed a predictive potential of microbiome-associated metabolites in the diagnosis of dementia. A higher concentration of fecal ammonia and lactic acid indicated the presence of dementia and had a similar predictive value as traditional biomarkers for dementia [118].

Furthermore, as described previously, the gut-brain-axis affects several functions in the brain, such as the regulation of the HPA axis, rule actions in the periphery and central nervous system, producing neurotransmitter, endocrine hormones, immunomodulators on neuropeptides, which can all modulate dementia, but there is little research among elderly $[32,116,118]$.

Much more is known about the mechanisms behind gut microbiota and AD (Figure 3). The most widely accepted explanation for the pathogenesis of AD is the accumulation of amyloid plaques (extracellular) and neurofibrillary tangles (intracellular) [119]. Furthermore, neuroinflammation, mitochondrial dysfunction, cerebral hypoperfusion, and impairment in the calcium balance are considered in the pathogenesis of $\mathrm{AD}[119,120]$. As there are still major gaps in the understanding of the pathogenesis of $\mathrm{AD}$, it is recognized as an interaction between genetic and environmental factors [121]. Over the past decade, it has been hypothesized that AD may be associated with gut microbiota dysbiosis. Microbiota dysbiosis may lead to increased permeability of the gut and blood-brain barrier, secretion of large amounts of microbial amyloids, lipopolysaccharides, neurotransmitters, and neurotoxins. Furthermore, imbalances in gut microbiota can induce inflammation, neuroinflammation, and oxidative stress. 


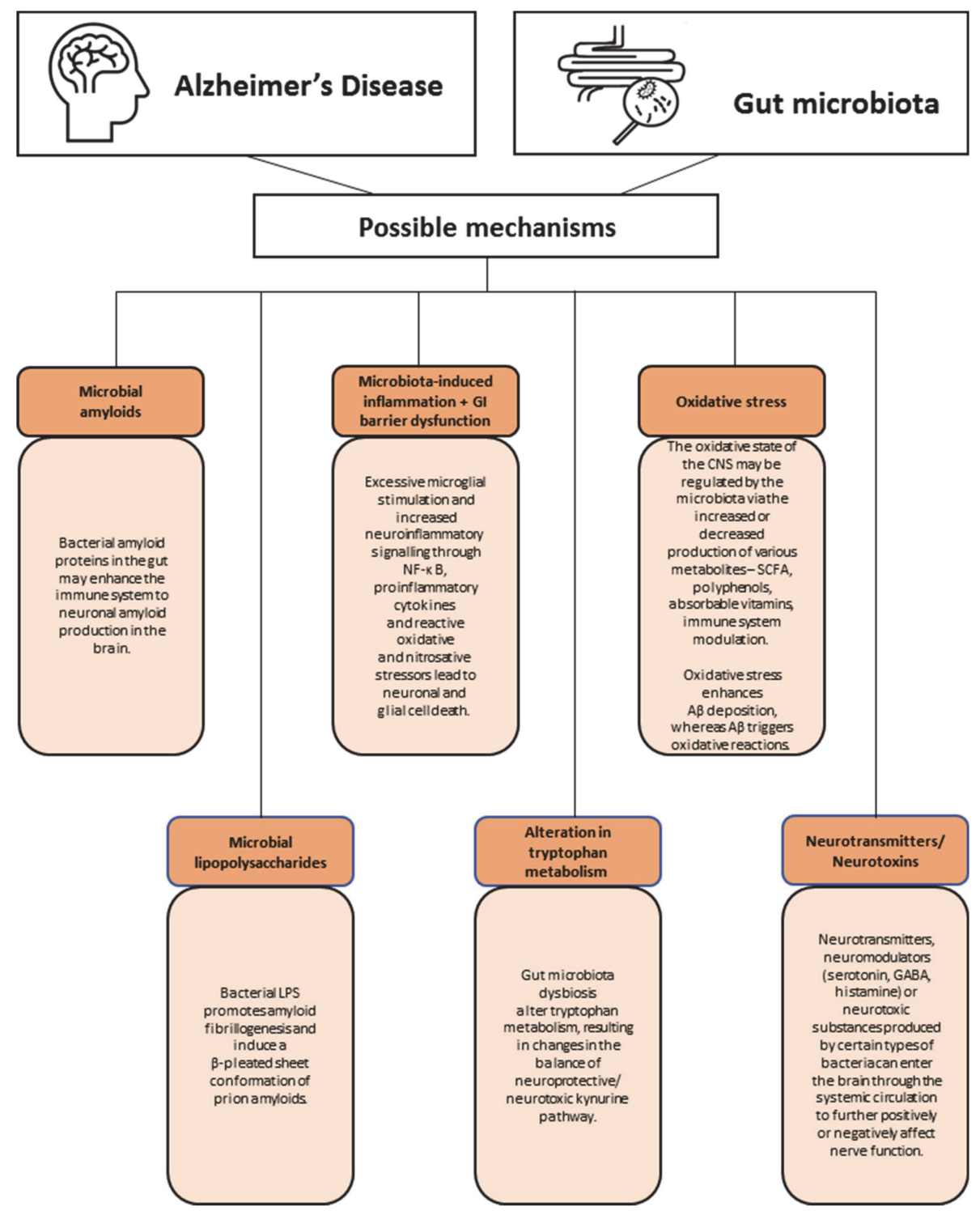

Figure 3. Possible mechanisms behind gut microbiota and Alzheimer's Disease (AD). Abbreviations: CNS, central nervous system; GABA, $\gamma$-aminobutyric acid; SCFA, short-chain fatty acids.

In 2017, the new term "mapranosis" was proposed, representing microbiota-associated proteopathy and neuroinflammation [122]. One of the possible mechanisms underlying the link between gut microbiota and $\mathrm{AD}$ is the promotion of amyloid formation by human proteins [122]. The gut microbiota produces a significant number of amyloids [122], although microbial amyloids differ from the human CNS amyloids (they have similarities in tertiary structure) [123-125]. Examples of such bacteria are Escherichia, Bacillus subtilis, Salmonella enterica, and Salmonella typhimurium [122,126,127]. Bacterial amyloid proteins in the gut may enhance the immune system to neuronal amyloid production in the brain. Bacterial amyloids may act as prion proteins, causing the amyloidogenic protein to adopt a pathogenic $\beta$-structure [128]. Furthermore, microbial amyloids may enhance the inflammatory response to endogenous neuronal amyloids [122].

Another possible mechanism proposes that lipopolysaccharides (LPS) may play a role in AD. Recently, E. coli and B. fragilis have been shown to intensely produce proinflammatory lipopolysaccharides (LPS), which can access brain compartments by crossing the gastrointestinal tract (GI tract) and blood-brain barrier [129]. The LPS presence in the brain (hippocampus and neocortex) has been detected post-mortem in AD patients [129]. In addition, AD patients had a 3-fold higher plasma concentration of LPS compared to healthy 
people [129]. Furthermore, recent intervention animal studies showed that bacterial LPS may induce a $\beta$-structure of prion amyloids and promote amyloid fibrillogenesis. There is also the hypothesis of a vicious cycle that is responsible for the progression of $\mathrm{AD}$ [130]. The hypothesis assumes that LPS, by acting on leukocyte and microglial TLR4-CD14/TLR2 receptors, increases $A \beta$ levels (via the increased level of cytokines), while $A \beta 1-42$ is an agonist for TLR4 receptors [130]. An increased level of cytokines also leads to damage of oligodendrocytes and produces myelin injury in the AD brain [130].

Over the years, inflammation has been implicated in AD pathogenesis, while recently, one of the sources for this inflammation has been indicated in GI. One of the markers of intestinal inflammation is calprotectin concentration in the stool [131]. Calprotectin is a heterodimer of proteins S100A8 and S100A9, which can form amyloid oligomers and fibrils resembling amyloid polypeptides, such as amyloid $\beta$ and $\alpha$-syn [131,132]. Kowalski et al. hypothesized that it is possible that intestinal calprotectin may contribute to amyloid fibril formation both in the gut or directly in the brain [128]. Recent studies showed that $70 \%$ of $A D$ patients had a significantly elevated level of fecal calprotectin [133] compared to controls. It was also shown that S100A9 expression was increased in the brains of AD mice and AD patients [134]. These results are in line with a recent study, which indicated a significantly increased S100A9 level in the cerebrospinal fluid of AD patients [135]. The neuroinflammatory state has been implicated in AD and proposed to facilitate neurodegeneration [136]. The immune system's hyperstimulation may be harmful to neurons and may lead to neuroinflammation when neurons release substances that sustain the inflammatory process and the immune response [37]. Cattaneo et al. showed that compared to controls, in patients with cognitive impairment and brain amyloidosis, an increase in the abundance of a proinflammatory Escherichia/Shigella and a reduction in an anti-inflammatory E. rectale were observed simultaneously [52]. Furthermore, a significant positive correlation was observed between pro-inflammatory cytokines IL- $1 \beta$, NLRP3, and CXCL2 with an abundance of Escherichia/Shigella and a negative correlation with the E. rectale [52]. Furthermore, the production of other proinflammatory cytokines may be induced indirectly by gut microbiota. For example, proinflammatory taxons that can secrete the previously mentioned amyloid peptide curli indirectly activate the production of IL-6, IL-1 $\beta$ [137], IL-17A, and IL-22 [138]. Some of the cytokines are able to cross the blood-brain barrier and lead to neuroinflammation and neurodegeneration [139]. Furthermore, gut microbiota can modulate the circulating concentration of tryptophan (Trp), which in $95 \%$ is metabolized through the kynurenine pathway (KP). KP results in the production of neuroprotective kynurenic acid (KYN), 3-hydroxyanthranilic acid (3HAA) (with antioxidant properties), as well as neurotoxic metabolites such as metabolites 3-hydroxykynurenine (3-HK) and quinolinic acid (QUIN) [140-142]. The observations linking the $\mathrm{KP}$ and $\mathrm{AD}$ include decreased tryptophan and 3-HAA concentrations in $\mathrm{AD}$ plasma, increased KYN/Trp ratio and 3-HK in serum of AD patients compared to elderly controls, and accumulation of QUIN in the hippocampus of AD patients [141,143-145]. Gut microbiota dysbiosis alters tryptophan metabolism, resulting in changes in the balance of the neuroprotective/neurotoxic kynurenine pathway, which seems to play an important role in $\mathrm{AD}$ pathology by leading to neuroinflammation [140].

Furthermore, the role of gut microbiota in regulating the oxidative state of the CNS may not be forgotten. Oxidative stress plays a significant role in AD pathology (e.g., enhances $\mathrm{A} \beta$ deposition), while antioxidant treatment effects in the retardation of the progression of $\mathrm{AD}$ [146]. In healthy individuals, gut microbiota may regulate the oxidative state via the production of various metabolites (SCFA, polyphenols, and absorbable vitamins) and enzymes (superoxide dismutase and catalase) [147-149], whereas if microbiota dysbiosis occurs, the ability to interfere with the level of reactive oxygen species (ROS) fades and the antioxidant defense system weakens [150]. Several studies showed increased peroxidation in AD patients and decreased levels of antioxidant molecules and activity of antioxidant enzymes. Shao et al. identified oxidative modifications to DNA and RNA via high levels of 8-hydroxy-2'-deoxyguanosine (8-OHdG) in the brain [151]. While differences 
in the activity of superoxide dismutase (SOD), glutathione peroxidase (GPx), 8-oxyguanine DNA glycosylase-1 (OGG1), and catalase (CAT), and levels of glutathione (GSH) and total antioxidant capacity (TAC) may indicate decreased activity of antioxidant enzyme systems among AD patients [151-153]. In addition, many researchers showed that probiotics demonstrate antioxidant abilities and could exert antioxidant capacity in different ways [154]. Tamtaji et al. showed that probiotic and selenium co-supplementation with selenium was associated with a significant increase in total antioxidant capacity and decreased levels of high sensitivity C-reactive protein (hs-CRP) among AD patients [102]. Den et al., in a meta-analysis of randomized controlled trials among adults with Alzheimer's or mild cognitive impairment, showed a significant improvement in cognition, while a significant decrease in levels of malondialdehyde (MDA) and hs-CRP between probiotics and the control group. No significant differences in TAC and GSH were found between groups [96]. Recent studies also indicate that prebiotic and synbiotic supplementation may also have significant ability to improve metabolic activity and improve cognition in $\mathrm{AD}$ patients. Synbiotics showed to increase bioavailability of microbially produced antioxidant metabolites, enhancing activity of antioxidant systems and improving cognitive function among AD patients $[155,156]$. Within possible mechanisms behind AD, there is also one related to the secretory function of gut microbiota, which may modulate brain plasticity, affect cognitive function and develop $\mathrm{AD}$ via other than previously mentioned neurotransmitters and neuromodulators (e.g., serotonin, GABA, and histamine), or neurotoxic metabolites (e.g., D-lactic acid and ammonia) [38,113,131].

To sum up, the gut microbiota may secrete significant amounts of amyloids and lipopolysaccharides, which can enhance inflammatory response to endogenous neuronal amyloids and increase the proinflammatory production of cytokines associated with the pathogenesis of AD. Furthermore, microbiota dysbiosis may lead to increased permeability of the gut and blood-brain barrier and modulation of the kynurenine pathway. In this position, transmitters and neurotoxic substances can easily enter the brain, affect nerve function, and lead to the development or progression of cognitive impairment and AD. All of the mentioned possible mechanisms may play a part simultaneously. Naturally, AD is probably associated with multiple pathomechanisms and etiologies; gut microbiota appears as a significant part of the pathophysiologic process. A significant limitation of most studies investigating microbiota's role in AD pathomechanism is that they are animal studies or cross-sectional studies. This causes difficulties in establishing an association between gut microbiota and the development/progression of AD. Additional case-control and prospective studies (including post-mortem studies) among patients with $\mathrm{AD}$ are required to better understand the link between gut microbiota and cognitive function/disease.

\section{Conclusions}

Over the recent years, growing interest in the relation between gut microbiota and cognitive function, especially in the elderly is observed, but there are still major gaps in our understanding of these interactions. Gut microbiota of cognitively healthy and impaired elderly people may differ in the diversity and abundance of individual taxes, but due to the small number of studies and divergent results, only some tendency to changing the Firmicutes/Bacteroidetes ratio can be identify. There will be interesting to find some specific taxes of microorganisms that could be serve as a marker of early stage of dementia. Such factors will be extremely important in preventing cognitive impairment development.

Currently, clinical trials involving dietary interventions and supplementation with probiotics, prebiotics, and synbiotics have shown that there are premises for the claim that these factors can improve cognitive functions, however it was not shown that there is a single intervention beneficial to the elderly population. More reliable evidence from largescale, long-period RCT is needed. Previous heterogeneity of research outcomes impairs further insight into these relations. It is difficult to spot any unambiguous dependencies due to methodological difficulties and a multitude of factors influencing both cognitive functions and gut microbiota. The effects of probiotics supplementation seem to be greater 
on cognitively impaired individuals than those on healthy ones, but more proof is needed in this area. Despite that we know that the health-promoting effect of a probiotics depends on the strain, doses and duration of probiotics ingestion, there is still lack of studies compared different intervention, e.g., different genus or species, different doses. It is also unclear whether the effect will persist after the end of the intervention and for how long. Future studies should also consider the baseline of microbiota composition and dietary intake of included individuals. The results of such studies should provide scientific clues for the rational design of dietary intervention specific to groups of older adults, with particular emphasis on the safety of using probiotic and prebiotic products. These findings are of public health importance because of the rapidly aging population and increasing cases of cognitive function diseases. Whether gut microbiota, probiotics/synbiotics may improve or slow down the cognitive function decline in the elderly needs further study. What is more, it seems that personalized nutrition strategies will be particular importance in the future, which is already noticeable in growing interest in this area.

Author Contributions: Conceptualization, A.B.-D. and D.Z.; writing-original draft preparation, A.B.-D., M.K.S., D.G., and D.Z.; writing—review and editing, A.B.-D., M.K.S., D.G., and D.Z.; All authors have read and agreed to the published version of the manuscript.

Funding: This research received no external funding.

Institutional Review Board Statement: Not applicable.

Informed Consent Statement: Not applicable.

Data Availability Statement: Not applicable.

Conflicts of Interest: The authors declare no conflict of interest.

\section{References}

1. Jafari Nasabian, P.; Inglis, J.E.; Reilly, W.; Kelly, O.J.; Ilich, J.Z. Aging Human Body: Changes in Bone, Muscle and Body Fat with Consequent Changes in Nutrient Intake. J. Endocrinol. 2017, 234, R37-R51. [CrossRef]

2. Müller, L.; Di Benedetto, S.; Pawelec, G. The Immune System and Its Dysregulation with Aging. In Biochemistry and Cell Biology of Ageing: Part II Clinical Science; Subcellular Biochemistry; Harris, J.R., Korolchuk, V.I., Eds.; Springer: Singapore, 2019; Volume 91, pp. 21-43. ISBN 9789811336805.

3. Cai, L.; Chan, J.S.Y.; Yan, J.H.; Peng, K. Brain Plasticity and Motor Practice in Cognitive Aging. Front. Aging Neurosci. 2014, 6. [CrossRef] [PubMed]

4. Crous-Bou, M.; Minguillón, C.; Gramunt, N.; Molinuevo, J.L. Alzheimer's Disease Prevention: From Risk Factors to Early Intervention. Alzheimer's Res. Ther. 2017, 9, 71. [CrossRef]

5. Petersen, R.C. Mild Cognitive Impairment. Contin. Lifelong Learn. Neurol. 2016, 22, 404-418. [CrossRef] [PubMed]

6. Alzheimer's Disease International. Alzheimer's Disease International World Alzheimer Report 2019: Attitudes to Dementia; Alzheimer's Disease International: London, UK, 2019.

7. Marchesi, J.R.; Ravel, J. The Vocabulary of Microbiome Research: A Proposal. Microbiome 2015, 3, 31. [CrossRef] [PubMed]

8. Ruan, W.; Engevik, M.A.; Spinler, J.K.; Versalovic, J. Healthy Human Gastrointestinal Microbiome: Composition and Function After a Decade of Exploration. Dig. Dis. Sci. 2020, 65, 695-705. [CrossRef]

9. Mohajeri, M.H.; Brummer, R.J.M.; Rastall, R.A.; Weersma, R.K.; Harmsen, H.J.M.; Faas, M.; Eggersdorfer, M. The Role of the Microbiome for Human Health: From Basic Science to Clinical Applications. Eur. J. Nutr. 2018, 57, 1-14. [CrossRef]

10. Gaulke, C.A.; Sharpton, T.J. The Influence of Ethnicity and Geography on Human Gut Microbiome Composition. Nat. Med. 2018, 24, 1495-1496. [CrossRef]

11. Thursby, E.; Juge, N. Introduction to the Human Gut Microbiota. Biochem. J. 2017, 474, 1823-1836. [CrossRef]

12. Hillman, E.T.; Lu, H.; Yao, T.; Nakatsu, C.H. Microbial Ecology along the Gastrointestinal Tract. Microbes. Environ. 2017, 32, 300-313. [CrossRef]

13. Arumugam, M.; Raes, J.; Pelletier, E.; Le Paslier, D.; Yamada, T.; Mende, D.R.; Fernandes, G.R.; Tap, J.; Bruls, T.; Batto, J.-M.; et al. Enterotypes of the Human Gut Microbiome. Nature 2011, 473, 174-180. [CrossRef]

14. Ghaisas, S.; Maher, J.; Kanthasamy, A. Gut Microbiome in Health and Disease: Linking the Microbiome-Gut-Brain Axis and Environmental Factors in the Pathogenesis of Systemic and Neurodegenerative Diseases. Pharm. Ther. 2016, 158, 52-62. [CrossRef]

15. An, R.; Wilms, E.; Masclee, A.A.M.; Smidt, H.; Zoetendal, E.G.; Jonkers, D. Age-Dependent Changes in GI Physiology and Microbiota: Time to Reconsider? Gut 2018, 67, 2213-2222. [CrossRef] [PubMed]

16. Baumgart, M.; Snyder, H.M.; Carrillo, M.C.; Fazio, S.; Kim, H.; Johns, H. Summary of the Evidence on Modifiable Risk Factors for Cognitive Decline and Dementia: A Population-Based Perspective. Alzheimer's Dement. 2015, 11, 718-726. [CrossRef] [PubMed] 
17. Legdeur, N.; Heymans, M.W.; Comijs, H.C.; Huisman, M.; Maier, A.B.; Visser, P.J. Age Dependency of Risk Factors for Cognitive Decline. BMC Geriatr 2018, 18, 187. [CrossRef] [PubMed]

18. Xu, W.; Tan, L.; Wang, H.-F.; Jiang, T.; Tan, M.-S.; Tan, L.; Zhao, Q.-F.; Li, J.-Q.; Wang, J.; Yu, J.-T. Meta-Analysis of Modifiable Risk Factors for Alzheimer's Disease. J. Neurol. Neurosurg. Psychiatry 2015, 86, 1299-1306. [CrossRef] [PubMed]

19. Lynch, S.V.; Pedersen, O. The Human Intestinal Microbiome in Health and Disease. N. Engl. J. Med. 2016, 375, 2369-2379. [CrossRef] [PubMed]

20. Petersen, C.; Round, J.L. Defining Dysbiosis and Its Influence on Host Immunity and Disease. Cell Microbiol. 2014, 16, 1024-1033. [CrossRef] [PubMed]

21. Berg, G.; Rybakova, D.; Fischer, D.; Cernava, T.; Vergès, M.-C.C.; Charles, T.; Chen, X.; Cocolin, L.; Eversole, K.; Corral, G.H.; et al. Microbiome Definition Re-Visited: Old Concepts and New Challenges. Microbiome 2020, 8, 103. [CrossRef]

22. Salminen, S.; Collado, M.C.; Endo, A.; Hill, C.; Lebeer, S.; Quigley, E.M.M.; Sanders, M.E.; Shamir, R.; Swann, J.R.; Szajewska, H.; et al. The International Scientific Association of Probiotics and Prebiotics (ISAPP) Consensus Statement on the Definition and Scope of Postbiotics. Nat. Rev. Gastroenterol. Hepatol. 2021, 1-19. [CrossRef]

23. de Almada, C.N.; Almada, C.N.; Martinez, R.C.R.; Sant'Ana, A.S. Paraprobiotics: Evidences on Their Ability to Modify Biological Responses, Inactivation Methods and Perspectives on Their Application in Foods. Trends Food Sci. Technol. 2016, 58, 96-114. [CrossRef]

24. Gibson, G.R.; Probert, H.M.; Loo, J.V.; Rastall, R.A.; Roberfroid, M.B. Dietary Modulation of the Human Colonic Microbiota: Updating the Concept of Prebiotics. Nutr. Res. Rev. 2004, 17, 259-275. [CrossRef]

25. Hill, C.; Guarner, F.; Reid, G.; Gibson, G.R.; Merenstein, D.J.; Pot, B.; Morelli, L.; Canani, R.B.; Flint, H.J.; Salminen, S.; et al. The International Scientific Association for Probiotics and Prebiotics Consensus Statement on the Scope and Appropriate Use of the Term Probiotic. Nat. Rev. Gastroenterol. Hepatol. 2014, 11, 506-514. [CrossRef] [PubMed]

26. Dinan, T.G.; Stanton, C.; Cryan, J.F. Psychobiotics: A Novel Class of Psychotropic. Biol. Psychiatry 2013, 74, 720-726. [CrossRef] [PubMed]

27. Pandey, K.R.; Naik, S.R.; Vakil, B.V. Probiotics, Prebiotics and Synbiotics-A Review. J. Food Sci. Technol. 2015, 52, 7577-7587. [CrossRef]

28. Bratburd, J.R.; Keller, C.; Vivas, E.; Gemperline, E.; Li, L.; Rey, F.E.; Currie, C.R. Gut Microbial and Metabolic Responses to Salmonella Enterica Serovar Typhimurium and Candida albicans. mBio 2018, 9, e02032-18. [CrossRef]

29. Vaiserman, A.M.; Koliada, A.K.; Marotta, F. Gut Microbiota: A Player in Aging and a Target for Anti-Aging Intervention. Ageing Res. Rev. 2017, 35, 36-45. [CrossRef]

30. Claesson, M.J.; Jeffery, I.B.; Conde, S.; Power, S.E.; O'Connor, E.M.; Cusack, S.; Harris, H.M.B.; Coakley, M.; Lakshminarayanan, B.; O'Sullivan, O.; et al. Gut Microbiota Composition Correlates with Diet and Health in the Elderly. Nature 2012, 488, 178-184. [CrossRef]

31. Alkasir, R.; Li, J.; Li, X.; Jin, M.; Zhu, B. Human Gut Microbiota: The Links with Dementia Development. Protein Cell 2017, 8, 90-102. [CrossRef]

32. Hopkins, M.J.; Macfarlane, G.T. Changes in Predominant Bacterial Populations in Human Faeces with Age and with Clostridium Difficile Infection. J. Med. Microbiol. 2002, 51, 448-454. [CrossRef]

33. Biagi, E.; Nylund, L.; Candela, M.; Ostan, R.; Bucci, L.; Pini, E.; Nikkïla, J.; Monti, D.; Satokari, R.; Franceschi, C.; et al. Through Ageing, and beyond: Gut Microbiota and Inflammatory Status in Seniors and Centenarians. PLoS ONE 2010, 5, e10667. [CrossRef]

34. Drago, L.; Toscano, M.; Rodighiero, V.; De Vecchi, E.; Mogna, G. Cultivable and Pyrosequenced Fecal Microflora in Centenarians and Young Subjects. J. Clin. Gastroenterol. 2012, 46, S81-S84. [CrossRef]

35. Askarova, S.; Umbayev, B.; Masoud, A.-R.; Kaiyrlykyzy, A.; Safarova, Y.; Tsoy, A.; Olzhayev, F.; Kushugulova, A. The Links Between the Gut Microbiome, Aging, Modern Lifestyle and Alzheimer's Disease. Front. Cell. Infect. Microbiol. 2020, 10. [CrossRef]

36. Senghor, B.; Sokhna, C.; Ruimy, R.; Lagier, J.-C. Gut Microbiota Diversity According to Dietary Habits and Geographical Provenance. Hum. Microbiome J. 2018, 7-8, 1-9. [CrossRef]

37. Angelucci, F.; Cechova, K.; Amlerova, J.; Hort, J. Antibiotics, Gut Microbiota, and Alzheimer's Disease. J. Neuroinflamm. 2019, 16. [CrossRef]

38. Whitelock, E.; Ensaff, H. On Your Own: Older Adults' Food Choice and Dietary Habits. Nutrients 2018, 10. [CrossRef]

39. Lindroos, E.K.; Saarela, R.K.T.; Suominen, M.H.; Muurinen, S.; Soini, H.; Kautiainen, H.; Pitkälä, K.H. Burden of Oral Symptoms and Its Associations with Nutrition, Well-Being, and Survival Among Nursing Home Residents. J. Am. Med. Dir. Assoc. 2019, 20, 537-543. [CrossRef]

40. Agarwal, E.; Miller, M.; Yaxley, A.; Isenring, E. Malnutrition in the Elderly: A Narrative Review. Maturitas 2013, 76, 296-302. [CrossRef]

41. Corish, C.A.; Bardon, L.A. Malnutrition in Older Adults: Screening and Determinants. Proc. Nutr. Soc. 2019, 78, 372-379. [CrossRef]

42. M Silva, F.; Petrica, J.; Serrano, J.; Paulo, R.; Ramalho, A.; Lucas, D.; Ferreira, J.P.; Duarte-Mendes, P. The Sedentary Time and Physical Activity Levels on Physical Fitness in the Elderly: A Comparative Cross Sectional Study. Int. J. Environ. Res. Public Health 2019, 16. [CrossRef]

43. Park, S.; Castaneda-Gameros, D.; Park, S.-Y.; Oh, I.-H. Factors of Physical Activity and Sedentary Behavior in Elderly Koreans. Am. J. Health Behav. 2019, 43, 1040-1049. [CrossRef] 
44. Codella, R.; Luzi, L.; Terruzzi, I. Exercise Has the Guts: How Physical Activity May Positively Modulate Gut Microbiota in Chronic and Immune-Based Diseases. Dig. Liver Dis. 2018, 50, 331-341. [CrossRef]

45. Rinninella, E.; Cintoni, M.; Raoul, P.; Lopetuso, L.R.; Scaldaferri, F.; Pulcini, G.; Miggiano, G.A.D.; Gasbarrini, A.; Mele, M.C. Food Components and Dietary Habits: Keys for a Healthy Gut Microbiota Composition. Nutrients 2019, 11, 2393. [CrossRef]

46. Schlegel, P.; Novotny, M.; Klimova, B.; Valis, M. "Muscle-Gut-Brain Axis": Can Physical Activity Help Patients with Alzheimer's Disease Due to Microbiome Modulation? J. Alzheimer's Dis. 2019, 71, 861-878. [CrossRef]

47. Heeney, D.D.; Gareau, M.G.; Marco, M.L. Intestinal Lactobacillus in Health and Disease, a Driver or Just along for the Ride? Curr. Opin. Biotechnol. 2018, 49, 140-147. [CrossRef] [PubMed]

48. Hidalgo-Cantabrana, C.; Delgado, S.; Ruiz, L.; Ruas-Madiedo, P.; Sánchez, B.; Margolles, A. Bifidobacteria and Their HealthPromoting Effects. Microbiol. Spectr. 2017, 5. [CrossRef]

49. Saji, N.; Niida, S.; Murotani, K.; Hisada, T.; Tsuduki, T.; Sugimoto, T.; Kimura, A.; Toba, K.; Sakurai, T. Analysis of the Relationship between the Gut Microbiome and Dementia: A Cross-Sectional Study Conducted in Japan. Sci. Rep. 2019, 9, 1008. [CrossRef]

50. Saji, N.; Murotani, K.; Hisada, T.; Tsuduki, T.; Sugimoto, T.; Kimura, A.; Niida, S.; Toba, K.; Sakurai, T. The Relationship between the Gut Microbiome and Mild Cognitive Impairment in Patients without Dementia: A Cross-Sectional Study Conducted in Japan. Sci. Rep. 2019, 9, 19227. [CrossRef]

51. Vogt, N.M.; Kerby, R.L.; Dill-McFarland, K.A.; Harding, S.J.; Merluzzi, A.P.; Johnson, S.C.; Carlsson, C.M.; Asthana, S.; Zetterberg, H.; Blennow, K.; et al. Gut Microbiome Alterations in Alzheimer's Disease. Sci. Rep. 2017, 7, 13537. [CrossRef]

52. Cattaneo, A.; Cattane, N.; Galluzzi, S.; Provasi, S.; Lopizzo, N.; Festari, C.; Ferrari, C.; Guerra, U.P.; Paghera, B.; Muscio, C.; et al. Association of Brain Amyloidosis with Pro-Inflammatory Gut Bacterial Taxa and Peripheral Inflammation Markers in Cognitively Impaired Elderly. Neurobiol. Aging 2017, 49, 60-68. [CrossRef]

53. Stadlbauer, V.; Engertsberger, L.; Komarova, I.; Feldbacher, N.; Leber, B.; Pichler, G.; Fink, N.; Scarpatetti, M.; Schippinger, W.; Schmidt, R.; et al. Dysbiosis, Gut Barrier Dysfunction and Inflammation in Dementia: A Pilot Study. BMC Geriatr. 2020, 20, 248. [CrossRef]

54. Liu, P.; Wu, L.; Peng, G.; Han, Y.; Tang, R.; Ge, J.; Zhang, L.; Jia, L.; Yue, S.; Zhou, K.; et al. Altered Microbiomes Distinguish Alzheimer's Disease from Amnestic Mild Cognitive Impairment and Health in a Chinese Cohort. Brain Behav. Immun. 2019, 80, 633-643. [CrossRef]

55. Nagpal, R.; Neth, B.J.; Wang, S.; Craft, S.; Yadav, H. Modified Mediterranean-Ketogenic Diet Modulates Gut Microbiome and Short-Chain Fatty Acids in Association with Alzheimer's Disease Markers in Subjects with Mild Cognitive Impairment. EBioMedicine 2019, 47, 529-542. [CrossRef]

56. Cerajewska, T.L.; Davies, M.; West, N.X. Periodontitis: A Potential Risk Factor for Alzheimer's Disease. Br. Dent. J. 2015, 218, 29-34. [CrossRef]

57. Holmer, J.; Aho, V.; Eriksdotter, M.; Paulin, L.; Pietiäinen, M.; Auvinen, P.; Schultzberg, M.; Pussinen, P.J.; Buhlin, K. Subgingival Microbiota in a Population with and without Cognitive Dysfunction. J. Oral Microbiol. 2021, 13. [CrossRef]

58. Wang, R.P.-H.; Ho, Y.-S.; Leung, W.K.; Goto, T.; Chang, R.C.-C. Systemic Inflammation Linking Chronic Periodontitis to Cognitive Decline. Brain Behav. Immun. 2019, 81, 63-73. [CrossRef]

59. Olsen, I.; Singhrao, S.K. Is There a Link between Genetic Defects in the Complement Cascade and Porphyromonas Gingivalis in Alzheimer's Disease? J. Oral Microbiol. 2020, 12, 1676486. [CrossRef] [PubMed]

60. Zmora, N.; Suez, J.; Elinav, E. You Are What You Eat: Diet, Health and the Gut Microbiota. Nat. Rev. Gastroenterol. Hepatol. 2019, 16, 35-56. [CrossRef] [PubMed]

61. David, L.A.; Maurice, C.F.; Carmody, R.N.; Gootenberg, D.B.; Button, J.E.; Wolfe, B.E.; Ling, A.V.; Devlin, A.S.; Varma, Y.; Fischbach, M.A.; et al. Diet Rapidly and Reproducibly Alters the Human Gut Microbiome. Nature 2014, 505, 559-563. [CrossRef]

62. Wu, G.D.; Chen, J.; Hoffmann, C.; Bittinger, K.; Chen, Y.-Y.; Keilbaugh, S.A.; Bewtra, M.; Knights, D.; Walters, W.A.; Knight, R.; et al. Linking Long-Term Dietary Patterns with Gut Microbial Enterotypes. Science 2011, 334, 105-108. [CrossRef]

63. Leeming, E.R.; Johnson, A.J.; Spector, T.D.; Le Roy, C.I. Effect of Diet on the Gut Microbiota: Rethinking Intervention Duration. Nutrients 2019, 11, 2862. [CrossRef]

64. Singh, R.K.; Chang, H.-W.; Yan, D.; Lee, K.M.; Ucmak, D.; Wong, K.; Abrouk, M.; Farahnik, B.; Nakamura, M.; Zhu, T.H.; et al. Influence of Diet on the Gut Microbiome and Implications for Human Health. J. Transl. Med. 2017, 15, 73. [CrossRef] [PubMed]

65. Soltani, S.; Jayedi, A.; Shab-Bidar, S.; Becerra-Tomás, N.; Salas-Salvadó, J. Adherence to the Mediterranean Diet in Relation to All-Cause Mortality: A Systematic Review and Dose-Response Meta-Analysis of Prospective Cohort Studies. Adv. Nutr. 2019, 10, 1029-1039. [CrossRef] [PubMed]

66. Psaltopoulou, T.; Sergentanis, T.N.; Panagiotakos, D.B.; Sergentanis, I.N.; Kosti, R.; Scarmeas, N. Mediterranean Diet, Stroke, Cognitive Impairment, and Depression: A Meta-Analysis: Annals of Neurology. Ann. Neurol. 2013, 74, 580-591. [CrossRef] [PubMed]

67. Singh, B.; Parsaik, A.K.; Mielke, M.M.; Erwin, P.J.; Knopman, D.S.; Petersen, R.C.; Roberts, R.O. Association of Mediterranean Diet with Mild Cognitive Impairment and Alzheimer's Disease: A Systematic Review and Meta-Analysis. J. Alzheimer's Dis. 2014, 39, 271-282. [CrossRef] [PubMed]

68. Loughrey, D.G.; Lavecchia, S.; Brennan, S.; Lawlor, B.A.; Kelly, M.E. The Impact of the Mediterranean Diet on the Cognitive Functioning of Healthy Older Adults: A Systematic Review and Meta-Analysis. Adv. Nutr. 2017, 8, 571-586. [CrossRef] [PubMed] 
69. De Filippis, F.; Pellegrini, N.; Vannini, L.; Jeffery, I.B.; La Storia, A.; Laghi, L.; Serrazanetti, D.I.; Di Cagno, R.; Ferrocino, I.; Lazzi, C.; et al. High-Level Adherence to a Mediterranean Diet Beneficially Impacts the Gut Microbiota and Associated Metabolome. Gut 2016, 65, 1812-1821. [CrossRef] [PubMed]

70. Garcia-Mantrana, I.; Selma-Royo, M.; Alcantara, C.; Collado, M.C. Shifts on Gut Microbiota Associated to Mediterranean Diet Adherence and Specific Dietary Intakes on General Adult Population. Front. Microbiol. 2018, 9, 890. [CrossRef]

71. Mitsou, E.K.; Kakali, A.; Antonopoulou, S.; Mountzouris, K.C.; Yannakoulia, M.; Panagiotakos, D.B.; Kyriacou, A. Adherence to the Mediterranean Diet Is Associated with the Gut Microbiota Pattern and Gastrointestinal Characteristics in an Adult Population. Br. J. Nutr. 2017, 117, 1645-1655. [CrossRef]

72. Ghosh, T.S.; Rampelli, S.; Jeffery, I.B.; Santoro, A.; Neto, M.; Capri, M.; Giampieri, E.; Jennings, A.; Candela, M.; Turroni, S.; et al. Mediterranean Diet Intervention Alters the Gut Microbiome in Older People Reducing Frailty and Improving Health Status: The NU-AGE 1-Year Dietary Intervention across Five European Countries. Gut 2020, 69, 1218-1228. [CrossRef]

73. Doorduijn, A.S.; van de Rest, O.; van der Flier, W.M.; Visser, M.; de van der Schueren, M.A.E. Energy and Protein Intake of Alzheimer's Disease Patients Compared to Cognitively Normal Controls: Systematic Review. J. Am. Med. Dir. Assoc. 2019, 20, 14-21. [CrossRef] [PubMed]

74. Cao, G.-Y.; Li, M.; Han, L.; Tayie, F.; Yao, S.-S.; Huang, Z.; Ai, P.; Liu, Y.-Z.; Hu, Y.-H.; Xu, B. Dietary Fat Intake and Cognitive Function among Older Populations: A Systematic Review and Meta-Analysis. J. Prev. Alzheimer's Dis. 2019, 204-211. [CrossRef]

75. Ruan, Y.; Tang, J.; Guo, X.; Li, K.; Li, D. Dietary Fat Intake and Risk of Alzheimer's Disease and Dementia: A Meta-Analysis of Cohort Studies. Curr. Alzheimer's Res. 2018, 15, 869-876. [CrossRef]

76. Brainard, J.S.; Jimoh, O.F.; Deane, K.H.O.; Biswas, P.; Donaldson, D.; Maas, K.; Abdelhamid, A.S.; Hooper, L.; Ajabnoor, S.; Alabdulghafoor, F.; et al. Omega-3, Omega-6, and Polyunsaturated Fat for Cognition: Systematic Review and Meta-Analysis of Randomized Trials. J. Am. Med. Dir. Assoc. 2020, 21, 1439.e21-1450.e21. [CrossRef] [PubMed]

77. Wolters, M.; Ahrens, J.; Romaní-Pérez, M.; Watkins, C.; Sanz, Y.; Benítez-Páez, A.; Stanton, C.; Günther, K. Dietary Fat, the Gut Microbiota, and Metabolic Health-A Systematic Review Conducted within the MyNewGut Project. Clin. Nutr. 2019, 38, 2504-2520. [CrossRef] [PubMed]

78. So, D.; Whelan, K.; Rossi, M.; Morrison, M.; Holtmann, G.; Kelly, J.T.; Shanahan, E.R.; Staudacher, H.M.; Campbell, K.L. Dietary Fiber Intervention on Gut Microbiota Composition in Healthy Adults: A Systematic Review and Meta-Analysis. Am. J. Clin. Nutr. 2018, 107, 965-983. [CrossRef]

79. Potì, F.; Santi, D.; Spaggiari, G.; Zimetti, F.; Zanotti, I. Polyphenol Health Effects on Cardiovascular and Neurodegenerative Disorders: A Review and Meta-Analysis. Int. J. Mol. Sci. 2019, 20. [CrossRef] [PubMed]

80. Ammar, A.; Trabelsi, K.; Müller, P.; Bouaziz, B.; Boukhris, O.; Glenn, J.M.; Bott, N.; Driss, T.; Chtourou, H.; Müller, N.; et al. The Effect of (Poly)Phenol-Rich Interventions on Cognitive Functions and Neuroprotective Measures in Healthy Aging Adults: A Systematic Review and Meta-Analysis. J. Clin. Med. 2020, 9. [CrossRef]

81. Ford, A.H.; Almeida, O.P. Effect of Vitamin B Supplementation on Cognitive Function in the Elderly: A Systematic Review and Meta-Analysis. Drugs Aging 2019, 36, 419-434. [CrossRef] [PubMed]

82. Goodwill, A.M.; Szoeke, C. A Systematic Review and Meta-Analysis of The Effect of Low Vitamin D on Cognition. J. Am. Geriatr. Soc. 2017, 65, 2161-2168. [CrossRef]

83. Etgen, T.; Sander, D.; Bickel, H.; Sander, K.; Förstl, H. Vitamin D Deficiency, Cognitive Impairment and Dementia: A Systematic Review and Meta-Analysis. Dement. Geriatr. Cogn. Disord. 2012, 33, 297-305. [CrossRef]

84. Waterhouse, M.; Hope, B.; Krause, L.; Morrison, M.; Protani, M.M.; Zakrzewski, M.; Neale, R.E. Vitamin D and the Gut Microbiome: A Systematic Review of in Vivo Studies. Eur. J. Nutr. 2019, 58, 2895-2910. [CrossRef]

85. Mullan, K.; Cardwell, C.R.; McGuinness, B.; Woodside, J.V.; McKay, G.J. Plasma Antioxidant Status in Patients with Alzheimer's Disease and Cognitively Intact Elderly: A Meta-Analysis of Case-Control Studies. J. Alzheimer's Dis. 2018, 62, 305-317. [CrossRef]

86. Rutjes, A.W.; Denton, D.A.; Di Nisio, M.; Chong, L.-Y.; Abraham, R.P.; Al-Assaf, A.S.; Anderson, J.L.; Malik, M.A.; Vernooij, R.W.; Martínez, G.; et al. Vitamin and Mineral Supplementation for Maintaining Cognitive Function in Cognitively Healthy People in Mid and Late Life. Cochrane Database Syst. Rev. 2018, 12. [CrossRef]

87. Coutts, L.; Ibrahim, K.; Tan, Q.Y.; Lim, S.E.R.; Cox, N.J.; Roberts, H.C. Can Probiotics, Prebiotics and Synbiotics Improve Functional Outcomes for Older People: A Systematic Review. Eur. Geriatr. Med. 2020, 11, 975-993. [CrossRef]

88. Romijn, A.R.; Rucklidge, J.J. Systematic Review of Evidence to Support the Theory of Psychobiotics. Nutr. Rev. 2015, 73, 675-693. [CrossRef]

89. Bedani, R.; Isay Saad, S.M.; Sivieri, K. Potential Benefits of Probiotics, Prebiotics, and Synbiotics on the Intestinal Microbiota of the Elderly. In Probiotics, Prebiotics, and Synbiotics; Elsevier: Amsterdam, The Netherlands, 2016; pp. 525-538. ISBN 978-0-12-802189-7.

90. Lv, T.; Ye, M.; Luo, F.; Hu, B.; Wang, A.; Chen, J.; Yan, J.; He, Z.; Chen, F.; Qian, C.; et al. Probiotics Treatment Improves Cognitive Impairment in Patients and Animals: A Systematic Review and Meta-Analysis. Neurosci. Biobehav. Rev. 2020, S014976342030631X. [CrossRef] [PubMed]

91. Benton, D.; Williams, C.; Brown, A. Impact of Consuming a Milk Drink Containing a Probiotic on Mood and Cognition. Eur. J. Clin. Nutr. 2007, 61, 355-361. [CrossRef] [PubMed]

92. Ohsawa, K.; Nakamura, F.; Uchida, N.; Mizuno, S.; Yokogoshi, H. Lactobacillus Helveticus -Fermented Milk Containing Lactononadecapeptide (NIPPLTQTPVVVPPFLQPE) Improves Cognitive Function in Healthy Middle-Aged Adults: A Randomised, Double-Blind, Placebo-Controlled Trial. Int. J. Food Sci. Nutr. 2018, 69, 369-376. [CrossRef] [PubMed] 
93. Chung, Y.-C.; Jin, H.-M.; Cui, Y.; Kim, D.S.; Jung, J.M.; Park, J.-I.; Jung, E.-S.; Choi, E.-K.; Chae, S.-W. Fermented Milk of Lactobacillus Helveticus IDCC3801 Improves Cognitive Functioning during Cognitive Fatigue Tests in Healthy Older Adults. J. Funct. Foods 2014, 10, 465-474. [CrossRef]

94. Kim, C.-S.; Cha, L.; Sim, M.; Jung, S.; Chun, W.Y.; Baik, H.W.; Shin, D.-M. Probiotic Supplementation Improves Cognitive Function and Mood with Changes in Gut Microbiota in Community-Dwelling Older Adults: A Randomized, Double-Blind, Placebo-Controlled, Multicenter Trial. J. Gerontol. Ser. A 2020, glaa090. [CrossRef]

95. Inoue, T.; Kobayashi, Y.; Mori, N.; Sakagawa, M.; Xiao, J.-Z.; Moritani, T.; Sakane, N.; Nagai, N. Effect of Combined Bifidobacteria Supplementation and Resistance Training on Cognitive Function, Body Composition and Bowel Habits of Healthy Elderly Subjects. Benef. Microbes 2018, 9, 843-853. [CrossRef] [PubMed]

96. Den, H.; Dong, X.; Chen, M.; Zou, Z. Efficacy of Probiotics on Cognition, and Biomarkers of Inflammation and Oxidative Stress in Adults with Alzheimer's Disease or Mild Cognitive Impairment-A Meta-Analysis of Randomized Controlled Trials. Aging 2020, 12, 4010-4039. [CrossRef]

97. Krüger, J.F.; Hillesheim, E.; Pereira, A.C.S.N.; Camargo, C.Q.; Rabito, E.I. Probiotics for Dementia: A Systematic Review and Meta-Analysis of Randomized Controlled Trials. Nutr. Rev. 2020, nuaa037. [CrossRef]

98. Hwang, Y.-H.; Park, S.; Paik, J.-W.; Chae, S.-W.; Kim, D.-H.; Jeong, D.-G.; Ha, E.; Kim, M.; Hong, G.; Park, S.-H.; et al. Efficacy and Safety of Lactobacillus Plantarum C29-Fermented Soybean (DW2009) in Individuals with Mild Cognitive Impairment: A 12-Week, Multi-Center, Randomized, Double-Blind, Placebo-Controlled Clinical Trial. Nutrients 2019, 11, 305. [CrossRef] [PubMed]

99. Kobayashi, Y.; Kuhara, T.; Oki, M.; Xiao, J.-Z. Effects of Bifidobacterium Breve A1 on the Cognitive Function of Older Adults with Memory Complaints: A Randomised, Double-Blind, Placebo-Controlled Trial. Benef. Microbes 2019, 10, 511-520. [CrossRef] [PubMed]

100. Agahi, A.; Hamidi, G.A.; Daneshvar, R.; Hamdieh, M.; Soheili, M.; Alinaghipour, A.; Esmaeili Taba, S.M.; Salami, M. Does Severity of Alzheimer's Disease Contribute to Its Responsiveness to Modifying Gut Microbiota? A Double Blind Clinical Trial. Front. Neurol. 2018, 9, 662. [CrossRef] [PubMed]

101. Akbari, E.; Asemi, Z.; Daneshvar Kakhaki, R.; Bahmani, F.; Kouchaki, E.; Tamtaji, O.R.; Hamidi, G.A.; Salami, M. Effect of Probiotic Supplementation on Cognitive Function and Metabolic Status in Alzheimer's Disease: A Randomized, Double-Blind and Controlled Trial. Front. Aging Neurosci. 2016, 8. [CrossRef]

102. Tamtaji, O.R.; Heidari-soureshjani, R.; Mirhosseini, N.; Kouchaki, E.; Bahmani, F.; Aghadavod, E.; Tajabadi-Ebrahimi, M.; Asemi, Z. Probiotic and Selenium Co-Supplementation, and the Effects on Clinical, Metabolic and Genetic Status in Alzheimer's Disease: A Randomized, Double-Blind, Controlled Trial. Clin. Nutr. 2019, 38, 2569-2575. [CrossRef] [PubMed]

103. Buigues, C.; Fernández-Garrido, J.; Pruimboom, L.; Hoogland, A.; Navarro-Martínez, R.; Martínez-Martínez, M.; Verdejo, Y.; Mascarós, M.; Peris, C.; Cauli, O. Effect of a Prebiotic Formulation on Frailty Syndrome: A Randomized, Double-Blind Clinical Trial. Int. J. Mol. Sci. 2016, 17, 932. [CrossRef]

104. Louzada, E.R.; Ribeiro, S.M.L. Synbiotic Supplementation, Systemic Inflammation, and Symptoms of Brain Disorders in Elders: A Secondary Study from a Randomized Clinical Trial. Nutr. Neurosci. 2020, 23, 93-100. [CrossRef]

105. Bowyer, R.C.E.; Jackson, M.A.; Pallister, T.; Skinner, J.; Spector, T.D.; Welch, A.A.; Steves, C.J. Use of Dietary Indices to Control for Diet in Human Gut Microbiota Studies. Microbiome 2018, 6, 77. [CrossRef] [PubMed]

106. Mueller, S.; Saunier, K.; Hanisch, C.; Norin, E.; Alm, L.; Midtvedt, T.; Cresci, A.; Silvi, S.; Orpianesi, C.; Verdenelli, M.C.; et al. Differences in Fecal Microbiota in Different European Study Populations in Relation to Age, Gender, and Country: A Cross-Sectional Study. Appl. Environ. Microbiol. 2006, 72, 1027-1033. [CrossRef] [PubMed]

107. Suez, J.; Zmora, N.; Elinav, E. Probiotics in the Next-Generation Sequencing Era. Gut Microbes 2020, 11,77-93. [CrossRef] [PubMed]

108. Johnson, A.J.; Zheng, J.J.; Kang, J.W.; Saboe, A.; Knights, D.; Zivkovic, A.M. A Guide to Diet-Microbiome Study Design. Front. Nutr. 2020, 7, 79. [CrossRef]

109. Sanders, M.E.; Akkermans, L.M.A.; Haller, D.; Hammerman, C.; Heimbach, J.T.; Hörmannsperger, G.; Huys, G. Safety Assessment of Probiotics for Human Use. Gut Microbes 2010, 1, 164-185. [CrossRef]

110. Hibberd, P.L.; Kleimola, L.; Fiorino, A.-M.; Botelho, C.; Haverkamp, M.; Andreyeva, I.; Poutsiaka, D.; Fraser, C.; Solano-Aguilar, G.; Snydman, D.R. No Evidence of Harms of Probiotic Lactobacillus Rhamnosus GG ATCC 53103 in Healthy Elderly-A Phase I Open Label Study to Assess Safety, Tolerability and Cytokine Responses. PLoS ONE 2014, 9, e113456. [CrossRef]

111. Liu, S.; Gao, J.; Zhu, M.; Liu, K.; Zhang, H.-L. Gut Microbiota and Dysbiosis in Alzheimer's Disease: Implications for Pathogenesis and Treatment. Mol. Neurobiol. 2020, 57, 5026-5043. [CrossRef] [PubMed]

112. Martin, C.R.; Osadchiy, V.; Kalani, A.; Mayer, E.A. The Brain-Gut-Microbiome Axis. Cell Mol. Gastroenterol. Hepatol. 2018, 6, 133-148. [CrossRef] [PubMed]

113. Quigley, E.M.M. Microbiota-Brain-Gut Axis and Neurodegenerative Diseases. Curr. Neurol. Neurosci. Rep. 2017, 17, 94. [CrossRef]

114. Gao, W.; Baumgartel, K.L.; Alexander, S.A. The Gut Microbiome as a Component of the Gut-Brain Axis in Cognitive Health. Biol. Res. Nurs. 2020, 22, 485-494. [CrossRef]

115. Zhu, F.; Li, C.; Chu, F.; Tian, X.; Zhu, J. Target Dysbiosis of Gut Microbes as a Future Therapeutic Manipulation in Alzheimer's Disease. Front. Aging Neurosci. 2020, 12. [CrossRef]

116. Ticinesi, A.; Tana, C.; Nouvenne, A.; Prati, B.; Lauretani, F.; Meschi, T. Gut Microbiota, Cognitive Frailty and Dementia in Older Individuals: A Systematic Review. Clin. Interv. Aging 2018, 13, 1497-1511. [CrossRef] [PubMed] 
117. Ferrucci, L.; Fabbri, E. Inflammageing: Chronic Inflammation in Ageing, Cardiovascular Disease, and Frailty. Nat. Rev. Cardiol. 2018, 15, 505-522. [CrossRef]

118. Saji, N.; Murotani, K.; Hisada, T.; Kunihiro, T.; Tsuduki, T.; Sugimoto, T.; Kimura, A.; Niida, S.; Toba, K.; Sakurai, T. Relationship between Dementia and Gut Microbiome-Associated Metabolites: A Cross-Sectional Study in Japan. Sci. Rep. 2020, 10, 8088. [CrossRef] [PubMed]

119. Long, J.M.; Holtzman, D.M. Alzheimer Disease: An Update on Pathobiology and Treatment Strategies. Cell 2019, 179, 312-339. [CrossRef] [PubMed]

120. Bostanciklioğlu, M. The Role of Gut Microbiota in Pathogenesis of Alzheimer's Disease. J. Appl. Microbiol. 2019, 127, 954-967. [CrossRef] [PubMed]

121. Jagust, W. Imaging the Evolution and Pathophysiology of Alzheimer Disease. Nat. Rev. Neurosci. 2018, 19, 687-700. [CrossRef] [PubMed]

122. Friedland, R.P.; Chapman, M.R. The Role of Microbial Amyloid in Neurodegeneration. PLoS Pathog. 2017, 13. [CrossRef] [PubMed]

123. Hill, J.M.; Lukiw, W.J. Microbial-Generated Amyloids and Alzheimer's Disease (AD). Front. Aging Neurosci. 2015, 7. [CrossRef]

124. Zhao, Y.; Dua, P.; Lukiw, W. Microbial Sources of Amyloid and Relevance to Amyloidogenesis and Alzheimer's Disease (AD). J. Alzheimer's Dis. Parkinsonism 2015, 5, 177. [CrossRef]

125. Friedland, R.P. Mechanisms of Molecular Mimicry Involving the Microbiota in Neurodegeneration. J. Alzheimer's Dis. 2015, 45, 349-362. [CrossRef]

126. Hufnagel, D.A.; Tükel, Ç.; Chapman, M.R. Disease to Dirt: The Biology of Microbial Amyloids. PLoS Pathog. 2013, 9, e1003740. [CrossRef] [PubMed]

127. Schwartz, R.H. Marijuana: A Decade and a Half Later, Still a Crude Drug with Underappreciated Toxicity. Pediatrics 2002, 109, 284-289. [CrossRef]

128. Kowalski, K.; Mulak, A. Brain-Gut-Microbiota Axis in Alzheimer's Disease. J. Neurogastroenterol. Motil. 2019, 25, 48-60. [CrossRef]

129. Zhao, Y.; Jaber, V.; Lukiw, W.J. Secretory Products of the Human GI Tract Microbiome and Their Potential Impact on Alzheimer's Disease (AD): Detection of Lipopolysaccharide (LPS) in AD Hippocampus. Front. Cell Infect. Microbiol. $2017,7$. [CrossRef] [PubMed]

130. Zhan, X.; Stamova, B.; Sharp, F.R. Lipopolysaccharide Associates with Amyloid Plaques, Neurons and Oligodendrocytes in Alzheimer's Disease Brain: A Review. Front. Aging Neurosci. 2018, 10. [CrossRef] [PubMed]

131. Derkacz, A.; Olczyk, P.; Komosinska-Vassev, K. Diagnostic Markers for Nonspecific Inflammatory Bowel Diseases. Dis. Markers 2018, 2018. [CrossRef] [PubMed]

132. Vatn, M.H.; Sandvik, A.K. Inflammatory Bowel Disease. Scand. J. Gastroenterol. 2015, 50, 748-762. [CrossRef]

133. Leblhuber, F.; Geisler, S.; Steiner, K.; Fuchs, D.; Schütz, B. Elevated Fecal Calprotectin in Patients with Alzheimer's Dementia Indicates Leaky Gut. J. Neural. Transm. 2015, 122, 1319-1322. [CrossRef]

134. Chang, K.-A.; Kim, H.J.; Suh, Y.-H. The Role of S100a9 in the Pathogenesis of Alzheimer's Disease: The Therapeutic Effects of S100a9 Knockdown or Knockout. Neurodegener. Dis. 2012, 10, 27-29. [CrossRef] [PubMed]

135. Horvath, I.; Jia, X.; Johansson, P.; Wang, C.; Moskalenko, R.; Steinau, A.; Forsgren, L.; Wågberg, T.; Svensson, J.; Zetterberg, H.; et al. Pro-Inflammatory S100A9 Protein as a Robust Biomarker Differentiating Early Stages of Cognitive Impairment in Alzheimer's Disease. ACS Chem. Neurosci. 2016, 7, 34-39. [CrossRef]

136. Minter, M.R.; Taylor, J.M.; Crack, P.J. The Contribution of Neuroinflammation to Amyloid Toxicity in Alzheimer's Disease. J. Neurochem. 2016, 136, 457-474. [CrossRef] [PubMed]

137. Rapsinski, G.J.; Wynosky-Dolfi, M.A.; Oppong, G.O.; Tursi, S.A.; Wilson, R.P.; Brodsky, I.E.; Tükel, Ç. Toll-like Receptor 2 and NLRP3 Cooperate to Recognize a Functional Bacterial Amyloid, Curli. Infect. Immun. 2015, 83, 693-701. [CrossRef]

138. Nishimori, J.H.; Newman, T.N.; Oppong, G.O.; Rapsinski, G.J.; Yen, J.-H.; Biesecker, S.G.; Wilson, R.P.; Butler, B.P.; Winter, M.G.; Tsolis, R.M.; et al. Microbial Amyloids Induce Interleukin 17A (IL-17A) and IL-22 Responses via Toll-Like Receptor 2 Activation in the Intestinal Mucosa. Infect. Immun. 2012, 80, 4398-4408. [CrossRef] [PubMed]

139. Erickson, M.A.; Dohi, K.; Banks, W.A. Neuroinflammation: A Common Pathway in CNS Diseases as Mediated at the Blood-Brain Barrier. Neuroimmunomodulation 2012, 19, 121-130. [CrossRef]

140. Garcez, M.L.; Jacobs, K.R.; Guillemin, G.J. Microbiota Alterations in Alzheimer's Disease: Involvement of the Kynurenine Pathway and Inflammation. Neurotox. Res. 2019, 36, 424-436. [CrossRef] [PubMed]

141. Schwarz, M.J.; Guillemin, G.J.; Teipel, S.J.; Buerger, K.; Hampel, H. Increased 3-Hydroxykynurenine Serum Concentrations Differentiate Alzheimer's Disease Patients from Controls. Eur. Arch. Psychiatry Clin. Neurosci. 2013, 263, 345-352. [CrossRef] [PubMed]

142. Smoller, J.W.R.S.; Lee, P.H.; Neale, B.; Nurnberger, J.I.; Santangelo, S.; Sullivan, P.F.; Schulze, T.G.; Thapar, A.; Anney, R.; Buitelaar, J.K.; et al. Identification of Risk Loci with Shared Effects on Five Major Psychiatric Disorders: A Genome-Wide Analysis. Lancet 2013, 381, 1371-1379. [CrossRef]

143. Giil, L.M.; Midttun, Ø.; Refsum, H.; Ulvik, A.; Advani, R.; Smith, A.D.; Ueland, P.M. Kynurenine Pathway Metabolites in Alzheimer's Disease. J. Alzheimer's Dis. 2017, 60, 495-504. [CrossRef]

144. Guillemin, G.J.; Williams, K.R.; Smith, D.G.; Smythe, G.A.; Croitoru-Lamoury, J.; Brew, B.J. Quinolinic Acid in the Pathogenesis of Alzheimer's Disease. Adv. Exp. Med. Biol. 2003, 527, 167-176. [PubMed]

145. Widner, B.; Leblhuber, F.; Walli, J.; Tilz, G.P.; Demel, U.; Fuchs, D. Tryptophan Degradation and Immune Activation in Alzheimer's Disease. J. Neural. Transm. 2000, 107, 343-353. [CrossRef] [PubMed] 
146. Huang, W.-J.; Zhang, X.; Chen, W.-W. Role of Oxidative Stress in Alzheimer's Disease. Biomed. Rep. 2016, 4, 519-522. [CrossRef] [PubMed]

147. Sharon, G.; Garg, N.; Debelius, J.; Knight, R.; Dorrestein, P.C.; Mazmanian, S.K. Specialized Metabolites from the Microbiome in Health and Disease. Cell Metab. 2014, 20, 719-730. [CrossRef] [PubMed]

148. Rowland, I.; Gibson, G.; Heinken, A.; Scott, K.; Swann, J.; Thiele, I.; Tuohy, K. Gut Microbiota Functions: Metabolism of Nutrients and Other Food Components. Eur. J. Nutr. 2018, 57, 1-24. [CrossRef] [PubMed]

149. Kullisaar, T.; Zilmer, M.; Mikelsaar, M.; Vihalemm, T.; Annuk, H.; Kairane, C.; Kilk, A. Two Antioxidative Lactobacilli Strains as Promising Probiotics. Int. J. Food Microbiol. 2002, 72, 215-224. [CrossRef]

150. Dumitrescu, L.; Popescu-Olaru, I.; Cozma, L.; Tulbă, D.; Hinescu, M.E.; Ceafalan, L.C.; Gherghiceanu, M.; Popescu, B.O. Oxidative Stress and the Microbiota-Gut-Brain Axis. Oxid. Med. Cell. Longev. 2018, 2018. [CrossRef]

151. Shao, C.; Xiong, S.; Li, G.-M.; Gu, L.; Mao, G.; Markesbery, W.R.; Lovell, M.A. Altered 8-Oxoguanine Glycosylase in Mild Cognitive Impairment and Late-Stage Alzheimer's Disease Brain. Free. Radic. Biol. Med. 2008, 45, 813-819. [CrossRef]

152. Pocernich, C.B.; Butterfield, D.A. Elevation of Glutathione as a Therapeutic Strategy in Alzheimer Disease. Biochim. Biophys. Acta 2012, 1822, 625-630. [CrossRef]

153. Marcus, D.L.; Thomas, C.; Rodriguez, C.; Simberkoff, K.; Tsai, J.S.; Strafaci, J.A.; Freedman, M.L. Increased Peroxidation and Reduced Antioxidant Enzyme Activity in Alzheimer's Disease. Exp. Neurol. 1998, 150, 40-44. [CrossRef]

154. Oniszczuk, A.; Oniszczuk, T.; Gancarz, M.; Szymańska, J. Role of Gut Microbiota, Probiotics and Prebiotics in the Cardiovascular Diseases. Molecules 2021, 26, 1172. [CrossRef] [PubMed]

155. Arora, K.; Green, M.; Prakash, S. The Microbiome and Alzheimer's Disease: Potential and Limitations of Prebiotic, Synbiotic, and Probiotic Formulations. Front. Bioeng. Biotechnol. 2020, 8, 537847. [CrossRef] [PubMed]

156. Ton, A.M.M.; Campagnaro, B.P.; Alves, G.A.; Aires, R.; Côco, L.Z.; Arpini, C.M.; Guerra e Oliveira, T.; Campos-Toimil, M.; Meyrelles, S.S.; Pereira, T.M.C.; et al. Oxidative Stress and Dementia in Alzheimer's Patients: Effects of Synbiotic Supplementation. Oxid. Med. Cell. Longev. 2020, 2020, e2638703. [CrossRef] [PubMed] 